
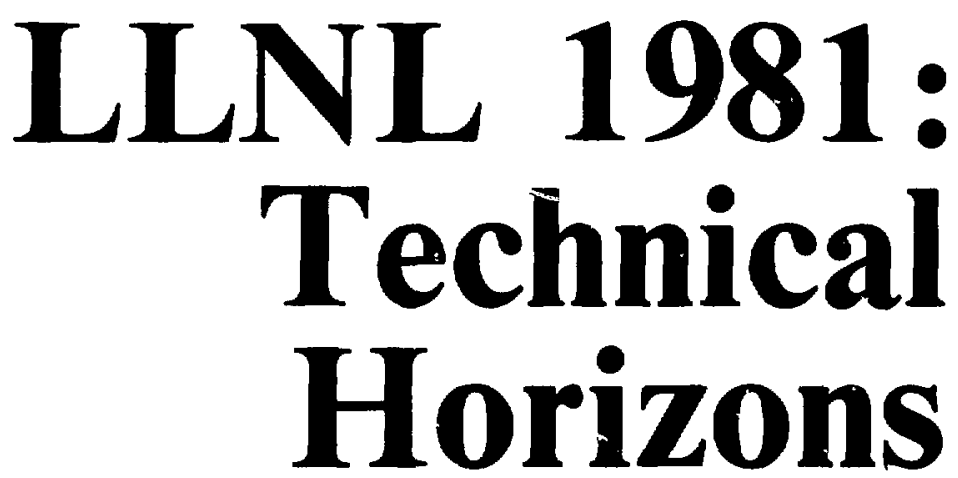

The Litwrente Livermore Nattional Laboratory was established in 1952 to conduct ntelear weapons restarch for the U.S. Government. Todiy, mosi of our work is done for the Department of Entrgy, and our staff has grown from the original fow hundred (o) nure than 7300 people. The secone of our research attivities hals also grown. Nuclear weapons reseitreh remains the single largest program, but we have also become decply involved in inertial confinenent fusion, magnetic fusion energy. applied energy lechnology, and hionedical and environmentil sciences, Our work is extending horizons in these fields and many more.

Nuclear weapons that shield us from attack are deemed essenutit to the defense of the country. The development of nuclear weapons is a continuing process as researeh reveals new possibilities, as worldwide developments dictate new requirenents, and as countermeitsures reduce the effectiveness of existing weapons. The task of developing these weapons, including laying the necessary scientific groundwork and understanding the phenomena of nuclear explosions, demands a wide spectrum of resources and skills drawn from scientific, engintering. and technical disciplines. LLNL has the breadth of expertise to function productively in this demanding area.

The energy produced in thernonuclear weapons is, in large part. the energy of thermonuclear fusion. One way of producing and studying fusion ractions in a controlled environment is to bring a tiny deutcrium-tritium fucl pellet to very high temperatures and densities in suth a short time that the thermonuclear fuel will ignite and burn hefore the compressed core disassembles. This lechnique, known is intertial confinement, relies upon a Uriver (e.g.. a haser) to deliver the extremely high-power. shorl-duration burst of energy required

Ous inerlial confinement fusion (ICF) program has both e vil and military goals. The misin civil application wolld be in the produc:ion of electricity. The military applications (far more casily realized) have 16) do with oblaining dalla on nuclear weapons physiess and ereating a sourec of radiation to simulate the: effects of nuclear weapons on militiry hardware (reentry vehicles, missiles. and sittellites), all without having to conduct an actual muelear test. Under a conuprehensive ban on nuclear lesting, ICF activities would be vital, unabling us to comtinue our studies: of important and challenging diagnostics problems and wo secruil and train new generallions of weapons experts.

There are other ways of controlling fusion reactions. One approach is to rely upon specially shaped magnetic fields to confine the thermonuclear fuel while heating it to fusion temperatures by somt external means. LLNL is conducting a vigorous magnetic fusion energy (MFE) research program, with the goal of developing the technology needed to harness thermonuclear fusion for power production. Successful development of a fusion reactor would give us practical aceess to fuels-deuterium (from water) and lithium-that will last for millennia. 


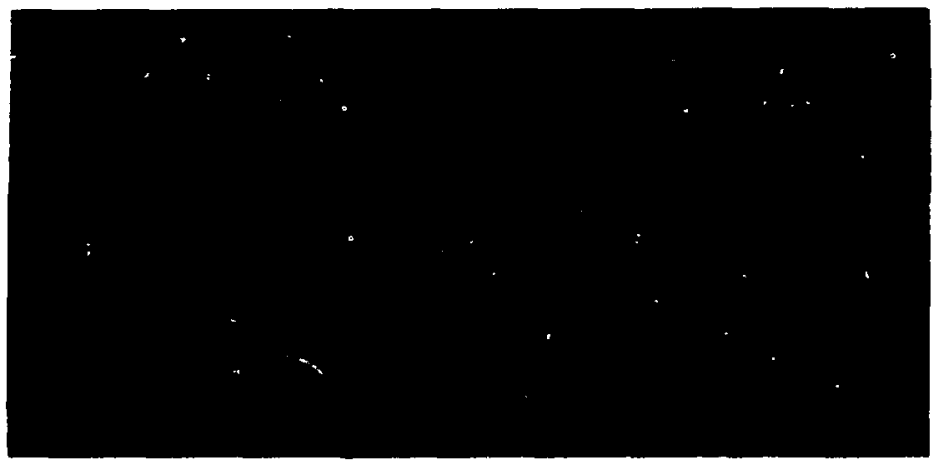

Good progress is being made in our effort to apply lasers to the separation of isotopes. This effort has been extended to include both defense applications and the carichment of uranium for power reictor fusl.

We are continuing otir afforts to develop such applied energy technologies as coal gasification and underground retorting of oil suale. LLNL has played a miljor role in the Departunent of Energy's progran to investigale coal gasificition-the underground conversion of coal into clean burning gases-as a promising prospect for an environmentally aleceptahle waly of tapping our huge coal resources. Wa have also worked for several years to develup an in sinu process for recovering oif liom shalk, Even though obstacles to large-stale develupment such as environmental impacts and institutional barricrs have prevented developments thill are now technically and economically feasible, dil shale remains a potentially valuabite energy resource.

In our hiomedical and environmental sciencen program, we are exploring the sources of energy-related pollutunts (both nuclear and nonnuclear), their methods of transport, and their effects on plants. animals, and humans. Studies range from prohes into the intimale workings of human cells to extensive surveys of entire ecousstems.

I ile major research programs at LLNL reyuire various internal support organizalions. These organizations, defined for the most part in terms of areati of technical specialization (chenuistry, physics, enginetring, computation, clc.), kecp pace with developments in the various disciplines and provide pools of well-trained professionils capable of lending their expertise to the new and constantly changing technieal problems faced in the major rescarch programs. The Laboratory's support organizations carry on sophisticated theiretical and experinental projects. maty of which have applications that serve not only the major LLNL programs but the interests of the broidder technicial community as vell.

The fulfillment of Laboratory commitments and programs requires the timely availability of programmattic resources in personnel and material. The efficient handling of these resources is supported by variouss administrative departments and divisions coordinaled through five mantegers under the acgis of an associale dïrector responsible for administration.

This issue of the Energy and Tedmology Review explores the technical horizons being defined by LLNL reseirchers in both support and programmatic roles.

Featured first is a summary of the annual Slate of the Laboratory address presented by the Director. Roger Batzel, on budgetary trends and the prospects for the future. Next is a sampling of achievenents, grouped under the three headings of national defense. energy and the environment, and support projects.t 


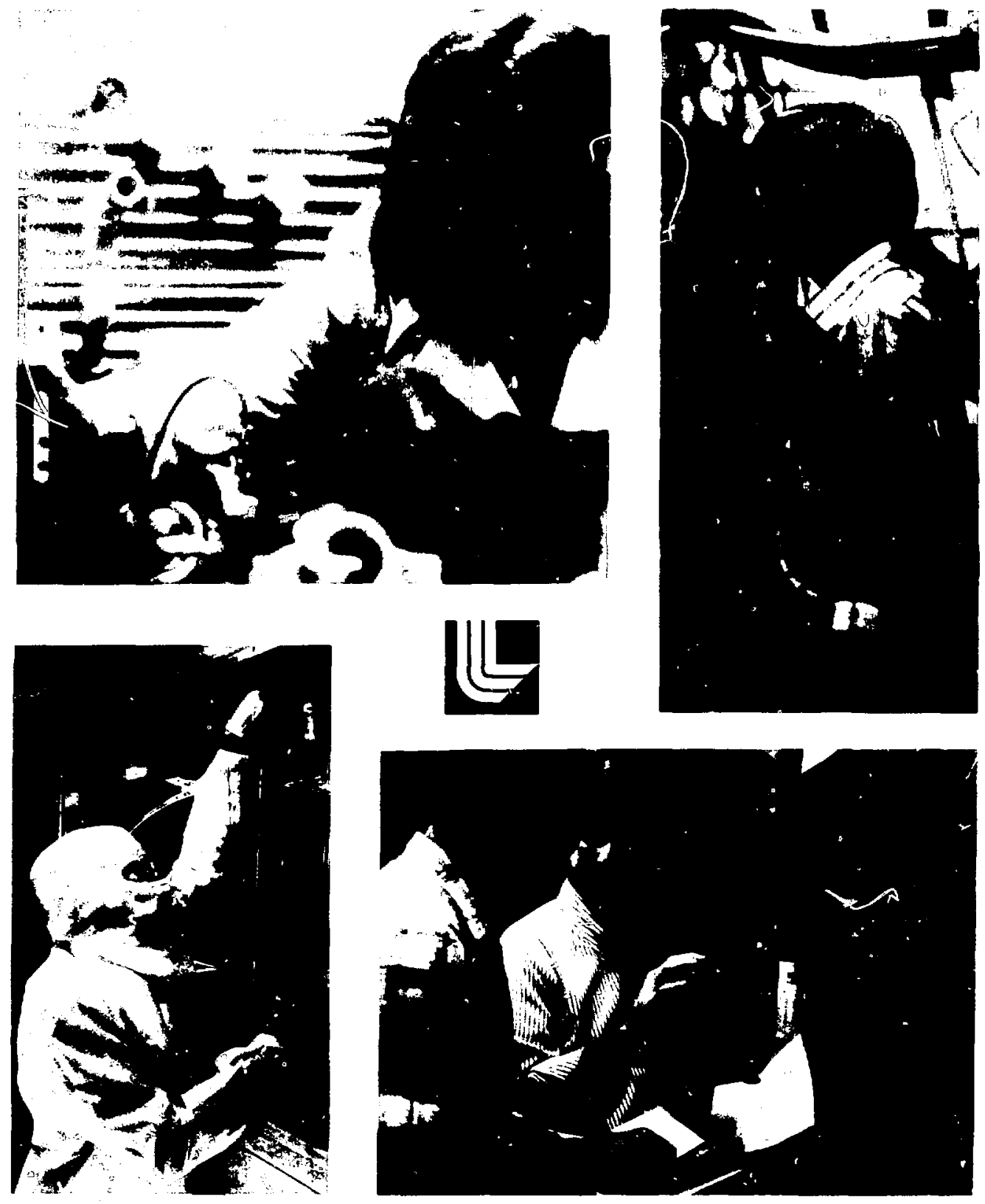




\section{The State of}
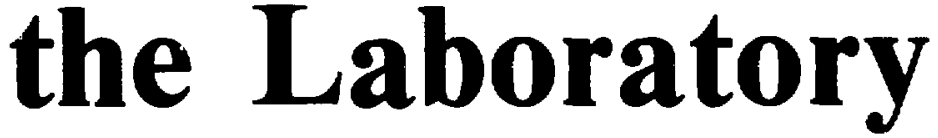

In his annual State of the Laboratory address,
Director Roger Batzel projected a $\$ 481$ million operating budget for fiscal year 1982, up nearly $13 \%$ from last year. He attributed this solid funding support to a shift in attitude at the national level and to skillful program planning and excellent staff perfor-

\section{mance over the years.}

Director Roger Batzel presented his State of the Laboratory address on June 11,1981 , unveiling a proposed $\$ 642$ million total budget and a \$481 million operating budget for fiscial year 1982. This budget provides for about a $13 \%$ increase in both budgel calegories (see Tables I and 2). When 10 (o) 12r; is subiricled for inflation. this represents a slight increasse in purchasing power. Batzel emphasized that the cuts suffered by a few programs are nore than offset by substantial inereases in many others. He also poinled out that these figures are tentiltive. subject to final approval hy Congress.

The largest single allociltion from the Department of Jinergy is for weapons research. It embudies the biggest increase in this area sine the Russians broke the moratorium on nuclear testing in 1961. Inertial confinement fusion remains the second laresest program at the Laboratory. even though funding has been somewhat reduced. Magnetic fusion energy will see a considerable inerease in funding. as will our two baser isotope separation programs-advanced isolope separation and special isotope separation-reflecting the excellent technical results achieved to date in all these programs. Funding for most other Laboratury programs is substantially increased. The biomedical and environmental program will sec only slight increases from the DOL: for the second consecutive sear. When the lhree IOOF entities in this areat are broken out by program slements at the l.aboratory. they show modest growth exeept lor envirumental sciences. which will sustitin a reduction in stifling.

Dr. Batlel noted that the proposed 19s? hudget reflects the change in adninistrition and the assotiatled shift in attitude at the national level. When atsked athout lite mood in Washington. D.C.. Bat/el stated thatl the emphasis an weapons research begiln during the latler years of the (arfer administration and is heing heightened by the new administration as the result of an evaluation of the military pesition of the U.S. in the world and a recognition that nuclear weapons are : fundamental part of our defense posturt.

Dr. Batzel commented briefly on how some of the programs will fare under the proposed 1982 budget. Although inflation will blunt the impact of all increases in funding, the \$33 inillion increase for weapons work will produce growth that will be of long-term benefit both to the program and to the nation. The Laboratory continues to be committed to developing warheads for new weapons systems. The budget increase will put us in 
Table 1 Total fimaminl activity. millions of dollars

\begin{tabular}{|c|c|c|}
\hline & $\begin{array}{l}\text { Rerised } \\
\text { FY 1981 }\end{array}$ & $\begin{array}{l}\text { Proposed } \\
\text { FY } 1982\end{array}$ \\
\hline Operations & S426.K & $\$ 481.1$ \\
\hline Fquipment & 33.8 & 42.1 \\
\hline General plant & 4.4 & 5.4 \\
\hline ronsinuction & 103.9 & 113.1 \\
\hline Total & 5568.9 & S6+1.7 \\
\hline
\end{tabular}

Table 2 I.1.Y. proupram funting. mlllisins iff dollurs.

\begin{tabular}{|c|c|c|}
\hline & $\begin{array}{l}\text { Nubiual } \\
\text { FY } 1981\end{array}$ & $\begin{array}{l}\text { Propousd } \\
\text { PY 19k2 }\end{array}$ \\
\hline \multicolumn{3}{|l|}{ Defenst prourams } \\
\hline Weapuns & $17 k, 9$ & 212.3 \\
\hline lacrtial confinement rusian & 酒 & 45 \\
\hline I crificalion and comirol & X.6 & III. I \\
\hline Safepuards und ecurity & 11.4 & 01.6 \\
\hline Isolope separation & (10.) & 14.8 \\
\hline Dofense nunte niallakement & 1.3 & $8 \mathrm{x}$ \\
\hline \multicolumn{3}{|l|}{ Fumil enures: } \\
\hline Cosal gasifteation and gav reconers & is & 3." \\
\hline oril wate & 30 & 3.4 \\
\hline Cias stimulation & 2.1 & $1:$ \\
\hline \multicolumn{3}{|l|}{ Conseration and remewable encrgs } \\
\hline Sillar Iechmetogy and urplikation & 1.5 & 11.- \\
\hline Tranypori cencres sonecrotion & 0.3 & 10.6 \\
\hline Fatrey storage yystemin & $\therefore 4$ & +.4 \\
\hline Givethermal & 1.0 & 11.6 \\
\hline \multicolumn{3}{|l|}{ Finurgs renearch } \\
\hline Varawetic rusion & $3+.11$ & +1.5 \\
\hline Varactic Fusion Compenter Cinter & 9.9 & $1 \because "$ \\
\hline lincres rewarch & 4.0 & 4.. \\
\hline Ilealth and envirummental rewarch & 1.2 & s.tu \\
\hline \multicolumn{3}{|l|}{ Vuciear entrg! } \\
\hline vdranced iwstupe wparatiun techmolugy & IN.9 & $2: 3$ \\
\hline Coummercial nuckear nasis & +.6 & $6,1)$ \\
\hline \multicolumn{3}{|l|}{$\begin{array}{l}\text { Finviromment, protection, safety, } \\
\text { and emergency prepareducss }\end{array}$} \\
\hline Vinsirtenmental extistities & 1.9 & 2.0 \\
\hline Lipuelied gacenus fucl programs & 3.7 & 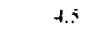 \\
\hline Other Department of Einergy & 11.0 & 13.1 \\
\hline Reimhersoble proprams and work for of hess & 5.7 & 10.1 \\
\hline Total & $\overrightarrow{426.8}$ & $\overline{+s 1.1}$ \\
\hline
\end{tabular}

a better position to test these warheads to ensure that they will indeed function as designed when incorporated into the nation's stockpile. The number of tests conducted at the Nevada Test Site in fiscal year 1982 is expected to increase over that in 1981. Advanced weapons development will benefit from the increased funding and the increased testing. enabling us to explore new concepts that have never heen tested hecaluse of limited resoures.

We have received approval to purchase two additional Crity computers, which will be installed in December 1981 and May 1982 and will provide a significunt improvement in our computational capability.

Attacl expressed pleasure at the solid support on as natiousal level for the t.aboratory's programs in magnctic fusion energy. In his opinion, fiscal year 1981 wils a banner yeir for these programs, and this support is well deserved. The Tandem Mirror Expuriment produced encouraging results, and the Magnetic Fusion Test Facility, currently under construction. will be a unique experimental resuurce. Butzel asserted that the magnetic mirror approach to magnutic fusion is a solid alternative to tukamaks and noted that there is at good possibility that the mannetic mireor approath will be the one chosen for the first demonstration facility.

In discetssing the seteral progrims and subprograms that fiace restrited hudgets in 1952. Battel recognised that there is only a limited amoun of money available for programss lik the l.aboratorys. In effect. it is a "/ero-sum game." where intrutists in some programs must some at the expense of others.

Regarding inertial confinement fusion (liser fusion). Batzel noted that, although the program had many solid achievements during the past year. a decision was malde by the government to reduce funding in this ared in the belief that some cuts could be achieved without serious consequences. Batzel stated that, in his view, these cuts should caluse only a lemporary slowdown. He noted that the Heuse Arned Services Committee has proposed additional lunding to correct the situation, although it is uncertain whether this itein will survive the remaining legislative action. 
Batzel pointed out that the limited funding in environmental sciences reflects the feeling in parts of the new administration that environmental issues have received too much emphasis in the past. These cuts reflect a decision to limit support in this areat until the situation is reevaluated. In this case, also, he views the reduced funding as a leniporary situation. He noted that biomedicil sciences has survived intact-a good decision, in his opinion.

The in sim esal gasification program shows a modest increase in liscal year 1982. inatsel staled that he believes the laboratory has an important role to play here over the next several years, In the long term. of course, this program will be turned over to industry. In Batzel's view. the laboratory's role should be to make technological advantes that will provide industry with the necessary confidence to invest its own money for commercial-seile developinent.

In summary, Batzel noted that the Laboratory"s budget is increasing slightly at a time when other federally funded institutions are facing cuts. He projected a staff increase of 150 people which, with replacement for normal attrition, means about 1000 new hires in fiscal year 1982. Reassignments will be available for those persons affected by decreases in programmatic budgets.

Batzel stated that growth at this time reflects both the increased attention being given to defense issues in general and the Laboratory's history of technically solid programs. The programss all the laborallory are the kinds that will conlinue to be supported by the rederal government because of the long-tern., essential natlure of the work. In his opinion, this is a proper role for the Iatboratory.

Butzel then discussed some of the problems facing the Laboratory in fiscal year 1982. The major problem continues to be inadequate facilities. There are nearly one thousand temporary trailers on site, evidence of the need for more permanent office space. There is also some lack of lahoratory space. We have been reasonably successful in getting new construction in the past few years, most of it in the form of laboratory facilities but also including the Core-1 office building, the new office building for the magnetic fusion program, and the office addition associated with the Nova laser fusion facility. Batzel noted that the House Armed Services Committee has proposed additional funds for two new construction projects--the weapons materials restarch and development facility and the highexplosive applieations program facility.

Regarding the stutus of the new fiveyear contract (duc to start October 1 , 1982) between the U.S. Department of Energy and the University of California for manugement of the two weapous laboratorics, Batzel explained that in their May 1981 meeting, the Regents decided more time was needed to study the proposed comeract thoroughly. Consequently, the vote on accepting the contract was delayed until the June meeting. Itiditor's note: On lume 19, the Regents approved the contract and delegated to President Saxon the authority to sign it.]

On the subject of collective bargaining. Batzel nuted that the curliest we could expect an election wuuld be late 1981 or early 1982. Myriad isstes must first be resolved-such as defining bargaining units and determining who are the supervisors. Batzel reaffirmed his belief that collective bargaining is not in the best inlerests of the Laboratory or of the people within the Laboratury. "The existing relationship is a good one. It has proved successful. I don't want to disrupt it because, in the long term, that would be very detrimental to the Laboratory."

In clusing. Dr. Batzel emphasized that. all in all, the Laboratory will fare very well in fiscal year 1982. The incrersing budget looks especially good when compared with budget cuts faced by many other government institutions. He concluded that the Laborutory's favorable position is a direct result of skillful program planning and excellent staff performance over the years. "We are an applied technology laboritory, we've chosen and conducled our programs well, our results are good, and thus we're viewed at tha national level as a successful

laboratory." 


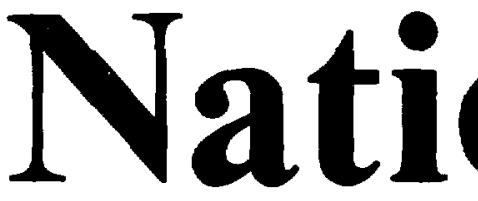

From the beginning, the Laboratory's main function has been to contribute to the development and maintenance of a stockpile of nuclear weapons capable of deterring any potential aggressor.

LLNL was established as and continues to be predominantly a nuclear weapons design laboratory, but over the years our expertise has been called upon in other areas of defense research as well: inertial confinement fusion (the production of fusion reactions by means of short, in. tense pulses of laser or particle-beam energy), nonnuclear ordnance (which requires many of the same technical facilities and capabilities as nuclear weapons research), and particle-beim technology.

Our nuclear weupors and inertial confinement fusion work is funded by the U.S. Department of Energy (DOE); the nonnuclear work is conducted under the auspices of the Department of Defense (DOD). We will discuss the LLNL program under two broad headings: Defonse Programs (DOE) and Defense Projects (DOD).

\section{Defense Programs (DOE)}

\section{ifucicer $\mathbf{W}$ cipons}

The nuclear weapons effort at LLNL involves three programs: nucleur design, nuclear testing, and military applications. 


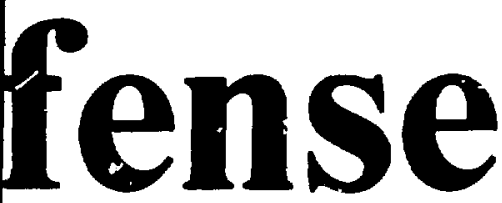

The goal of the nuclear design effort is to explore advanced weapons concepts and to improve our understanding of weapons physics. The nuclear test program has responsibility for fielding device tests at the Nevada Test Site. (This includes the design and construction of the downhule canister, shown on this puge, and the design and fielding of diagnostic equipment.) The military applications program is charged with developing a modern. reliable nuclear stockpile, initiating studies relating to the usefulness of nuclear weapons, and maintaining the current stockpile.

Nuclear design. Knowing what is possible in nuclear weaponry is important because it prevents our being surprised by a potential adversary. We are currently working on advanced designs that further enhance the safety and security of weapone and that tailor nuclear effects for specific purposes.

Nuclear designs that provide added safety also enhance security (e.g., by preventing the misuse of an illegally obtained weapon). Modern designs contain insensitive high explosive (IHE), which virtually eliminates the possibility of an accidental HE detonation due to impact or exposure to high temperatures. This, in turn, minimizes the likelihood of an accidental scattering of hazardous muterial. Some designs have separate vaults with layers of refractory material to contain the fissile material safely even if it melts.

Another recent development is the mechanical safe and arm detonator (MSAD), which operates by driving a thin aluminum flyer plate into a charge of IHE. Until it receives a 24-bit coded signal (after launch), the MSAD withiholds the high-explosive pellet that drives the flyer plate. Thus, the detonator is safe throughout its lifetime. MSAD can either augr: at or replace other safety devices used previously. 


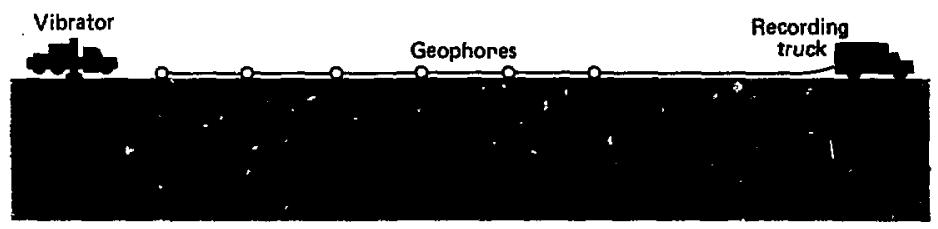

A schemenic representetion of seismicreflection mapping of sulsurface geology. A treck-moned vilurator sends a lowfrepency sound gignal into the grownd, and a serles of geophones detects the echoes. By comblaing information from a serles of sach meawrements recorded at difrerent lochtions, we can dedere the shapes of subsurface layers.
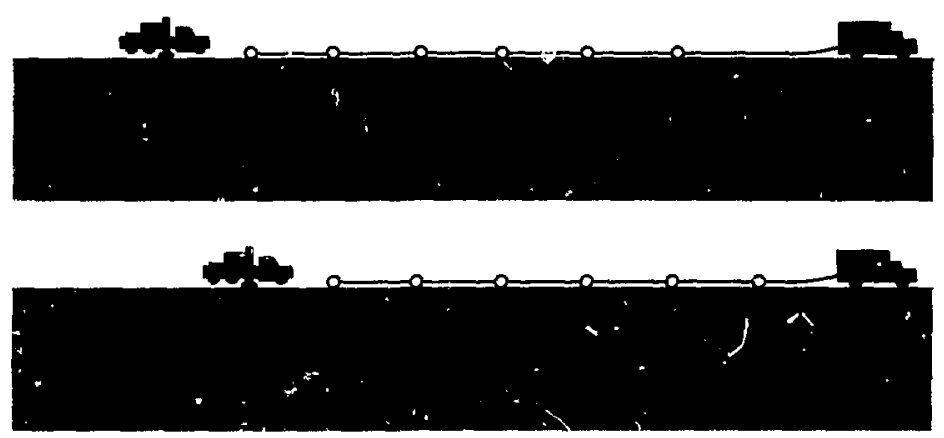

\section{The accrued results of our theoretical in- vestigations during recent years have laid the ground work for experimental and develop- riental programs to follow.}

In recent years, the testing of advanced nuclear devices has proceeded at a very slow pace, partly because the overall number of tests has been low and partly because most of the tests have been needed for designs that had reached the development engineering phase in anticipation of introduction into the stockpile. However, we have made progress in several key areas of advanced design, particularly in theoretical investigations.

The next several years offer a much brighter outlook for advanced development. As current weapons engineering development programs mature, their

New weapons also contain effective disablement features that can be activated manually or automatically. This makes it very unlikely that an unauthorized person would ever ojtain an intact, detonable nuclear weapon. Weapons with still more advanced safety features are under investigation.

We are working on designs that minimize fallout and blast in relation to prompt radiation. Tailored effects of this kind make it possible to achieve specific milit.ıry objectives while minimizing the collateral damage in surrounding communities and nonmilitary installations. testing level will decline, and, at the same time, the overall number of tests is expected to increase. These shifts should make possible a period of high achievement in advanced design work. Thus, the accrued results of our theoretical investigations during recent years have laid the grcundwork for experimental and developmental programs to follow.

Noclear testing. Nuclear testing involves far more than installing a device in a hole and detonating it. There is, for exaniple, the challenging problem of measuring significant explosion 
phenomena in many different ways in the brief peried of time available in an adverse environment far from conventional services. To meet this challenge, we are constantly developing new diagnostic instruments and techniques and upgrading our technology base. Much of this upgrading comes as a result of developments in private industry. However, where our requirements are unique, we ourselves develop the necessary new technology.

Microprocessors are having a mujor inpact on new instrumentation systems. They allow us to make instruments that culibrate and troubleshoot themselves, monitor their own output, adjust to shanging conditions, and operate unattended for extended periods. We are upplying this technology to provide fuster setup and more comprehensive and reliable system checks and to free our staff for more challenging and constructive tasks. In our control room at the Nevada Test Site, interactive graphics and alarm, control, and monitoring software afford us increased reliability as we conduct nuclear tests.

Another microprocessor-based system operates equipment in our X-ray Calibration and Standards Laboratory. This physics-information-gathering system allows us to use multichannel analyzers and acquire data without having operators in constant attendance. The system gives us more and better data, while sparing our technicians many hours of repetitious work.

We have recently begun to make use of wide-band fiber-optic cables to transmit high-speed data from new diagnostic systems on nuclear tests. Because they are nonconductive, fiber-optic materials transmit the signal more clearly (without electromagnetic noise). This improves the quality of data from present measurements, permits us to make new kinds of measurements, and reduces costs.

In planning otir Nevada tests, we must avoid drilling emplacement holes in areas that are geologically unsuitable. Therefore, we are adapting seismicreflection surveys (now in routine use in the mining and petroleum industries) to the special needs of the test program (Fig. 1). The Nevada Test Site, with its relatively thick and complex. layer of

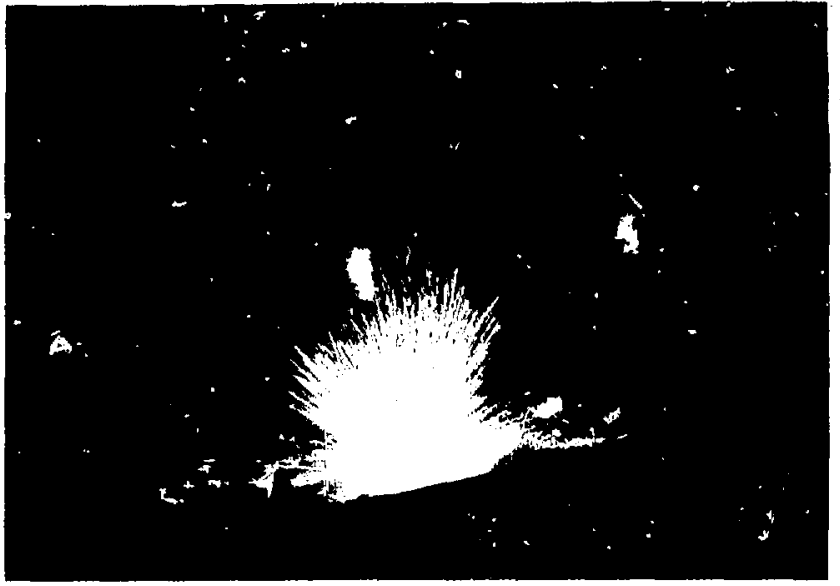

alluvium, poses special problems for this technology, but we have made considerable progress in coping with them. In the past year, we have begun to generate useful and reliable maps of the test site's subsurface geology.

In our continuing effort to evaluate the yield of nuclear devices by radiochemical means, we are placing increasing emphasis on analyzing gaseous materials, particularly the isotopes of hydrogen, helium, neon, krypton, and xenon. Because most of the informative isotopes of these elements are nonradioactive, we measure them by means of mass spectrometry. We have installed two new mass specirometers, which we are now using routinely on nuclear test sumples. They provide high sensitivities and improved accuracy.

Recent developments allow us to produce traveling-wave cathode-ray oscilloscopc tubes with greatly improved bandwidths. This advance was made possible by (a) the discovery of ways to install microchannel plates within the evacuated cathode-ray tube and (b) new enhanced phosphors that allow finer spot size and better definition.

At the Nevada Test Site, wè often need to examine either the equipment or the rocks deep in a hole or to work on downhole equipment. To permit such operations, we recently placed in service a 
Druc, a remote-centrolled robot camers

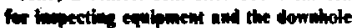
carironument in molenr-fest enplacements. Drome can le fitted to nrovile stereo ducuentratlon photegrains or five closedcircwit TV pictures. It is also eypipred to perform certain mechanical manipulations.

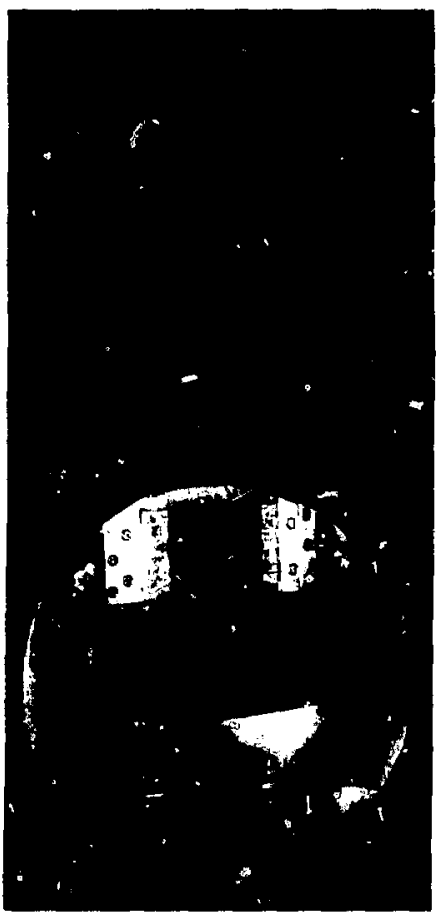

nexible robol package that allows stereo viewing. This package (Fig. 2), called Drone, can be lowered to provide television viewing, stereo and movie photography, and some downhole manipulation.

At Mercury, Nevada, we are building a facility in which to assemble and test downhole tools. It includes a hole $3 \mathrm{~m}$ in diameter and $36 \mathrm{~m}$ deep that provides a realistic environment in which to check tools and instruments used in geophysical logging.

We are also pursuing an entirely new technique for suspending :he many electrical and signal cables used in a nuclear test. A computer-controlled mechanical tensioner speeds the emplacement of the nuclear device and its diagnostic equipment. Our current procedures call for the attachment of the electrical cables to the emplacement pipe at frequent intervals (to maintain the proper tension). This requires much manpower and time ( 6 to 10 days). With the new system maintaining proper cable tension throughout the lnwering operation, we should be able to suspend each cable from the surface, reducing downhole time to 1 or 2 days and saving perhaps $\$ 2$ milljon per year.

Military applications. LLNL is charged with the responsibility of developing warheads for existing or proposed weapons-delivery systems, maintaining the existing stockpile, and evaluating the uses and effects of various weapons systems.

There are seven phuses to the nuclear weapons life cycle; conceptual studies, feasibility studies, development engineering, production engineering, first production, quantity production and stockpile maintenance, and retirement.

During the past year, we have concluded a feasibility study on warhead designs for a Trident-launched evader vehicle and on a warhead for the MX Advanced Ballistic Reentry Vehicle. (The development scinedule for these systems has not been decided.) We have also participated in a conceptual design study for a tactical air-to-ground missile.

With others in the ballistic missile defense community, we are working hard on ideas for a low-altitude defense system for the MX missile. Another feasibility study, for an upgraded antisubmarinewarfare capability, is prompted by the evolution of Soviet submarine speed and operational-depth capability.

LLNL warhead projects that have progressed beyond the conceptual design and feasibility stages are summarized in Fig. 3. Each poses unique challenges to the designers. The B83 strategic bomb must have rugged structural characteristics because in one of the delivery modes it is dropped by low-flying aircraft on hard, irregular targets. The W79 and W82 artillery shclls must be capable of withstanding enormous launch loads, and both must have baliistic properties comparable to those of nonnuclear rounds (so that the artillery can zero in on a target with conventional ordnance before the nuclear round is fired). The new Lance missile warhead (W70-4) must add new 
tactical capability to the missile system, as well as modern command and control systems, without altering the flight dynamics of the missile used for the $W 70-1$ and $W 70-2$. The $W / 84$ groundlaunched cruise missile warhead must incorporate many recently developed safety and security features that make it suitable for deployment in Europe. The W70-4 and the W84 represent new weapon! capabilities. The W79, W82, and B83 are being designed to replace weapons of lesser capability that have been in the stockpile for more than 20 yeurs.

As Fig. 3 illustrates, there was a burst of new development engineering projects in 1978-1979, hut no additional projects have been authorized for more than two years. We at a pleased that this decreusing development engineering work load, together with increasing weupons program resources, offers the prospect for a better balance between advanced development and development engineering.

Our responsibility for nuclear warheads does not end with production. We must also monitor and evaluate their reliability after they enter the stockpile. During the past year, as part of this effort, we conducted an underground nuclear test of a W68/MK3 ALT 304 warhead randomly selected from the production line. This stock pile-confidence test successfully demonstrated thie nuclear performance of the newly retrofitted W68 warhead for the Navy's submarine-launched Poseidon missile system. It also permitted us ' $n$ obtain modern prompt diagnostics on this system's performance.

nver the past year, we have made an overall analysis of the W70 stockpileevaluation program, concluding that it is unnecessarily stringent. We therefore reduced the sampling and testing requir: ments, effecting a saving in money and a reduction in the number of withdrawals from the W70 stockpile.

In support of the weapons design effort, steps have been taken this year to enhance engineering design and test facilities at LLNL. We have received authorization to build a thermal test building and an electrodynamic exciter building and to purchase associated test equipment. This $\$ 3.3$ million project is the first phase of a planned $\$ 8.6$ million, five-building $\mu$ rojcet that will bring our engineering test facilities up to iate and greatly facilitite warhead development work.

During the past year, we have brought into full operation a computer-aided design and drafting (CADD) system that can automatically rotate parts and move them about (on a display screen), provide isometric drawings, obtain surface intersections, pass cut planes through parts, and calculate mass properties. It reduces the initial design time, produces luyouts and detailed drawings much faster, and helps us detect errors enrlier. We have alsc procured a computer-controlled lathe and mill, which eventually will be linked to the CADD equipment, greatly simplifying and speeding the fabrication process.

One aspect of the military applicutions program that transcends pure engineering is planning and evaluation to determine how given weapons systems might be used and with what result. During the past year, we have developed and applied JANUS, a greatly improved two-sided interactive combat-simulation code for modeling an integrated (nuclear/ chemical/conventional) battlefield (see box, p. 14).

Another aspect of the military upplications progrum is illustruted by recent dosimetry studies of radiation exposure at Hiroshima and Nagasaki. Data on the radiation exposure of survivors of the Hiroshima and Nagasaki atomic bombs are a vital factor in the development of international protection standards for nuclear radiation. These data have been thought to be particularly valuable for this purpose because of the large neutron component of the initial radiation that was believed to have been present at Hiroshima (as compared to other available exposure data). However, the value of these data is limited by the accuracy with which the radiation dose of each individual surviver can be specified. Since 1965, this specification has been based on the T65D (tentative 1965 dose) pattern of neutron and gamna-ray dose estimates for all distances of interest at Hiroshima and Nagasaki.

We have made new free-in-air dose estimates that show changes in dose :us large as a factor of uine and reduce the 

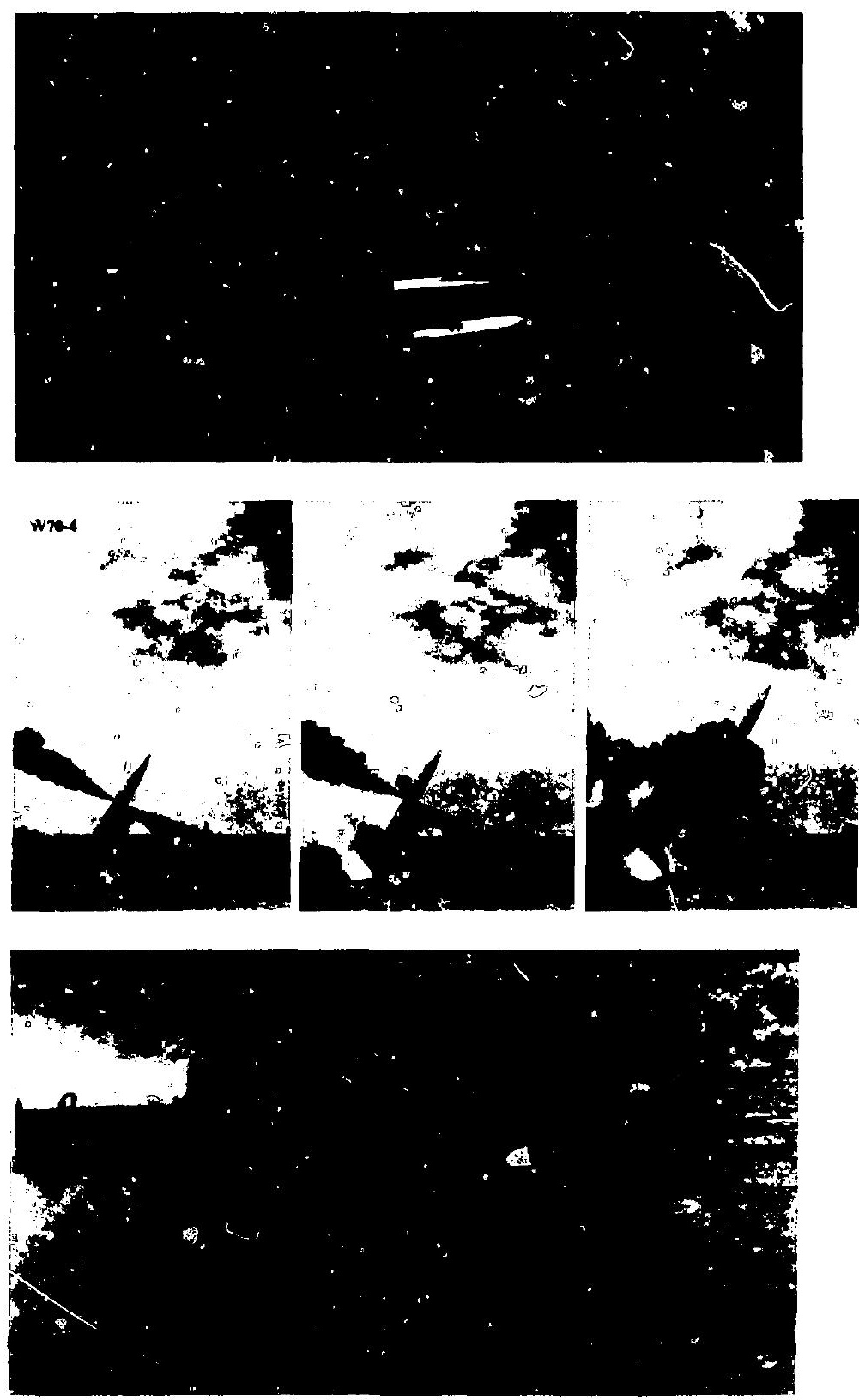


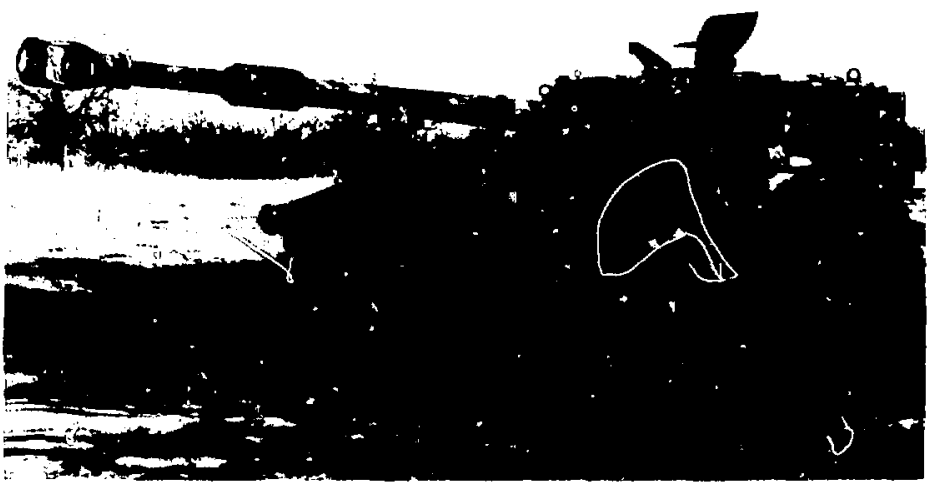

LINt. warkes projects currewly under development or in production engineeriag. In FY 1981. the 1eboratory will spend 5156 million on weapons projects.

Ba3: Modern strategec homb Authorized: Jalluars: 1974)

Status: Producturn engeincermg

W70-d: 1.ance surfinte-tu-surfice misstle Aulhorlzed: Ostuber 197\%

Stous: lnillil produtilom. $M$ \& 198 !

W79: X-11, howiter properte

Authorized: Jilluilry :975

Slatus: Inttiol mroduc:or, Juls |48|

WR2: 155.111m hawhes , c.1111m proptsilt:

tuthorized: Fehruiles 1978

Status: Deschipment

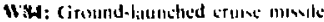
Suthorized: Octesher 197k

Sintus: Prodactaon entutuserung

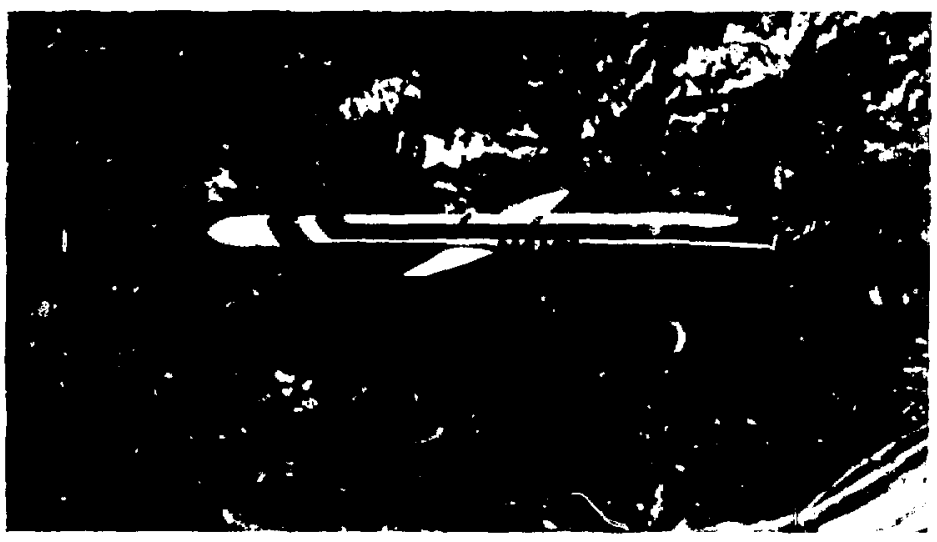


The Nora laser fasion researeh Iacility. mow wader censtruction, will provide otsearctiers with powerful new tools for the sudy of mockear weapons phystos and levet. tisl canfinemew fusion. Thus Heure shows banks for Nora's first five huning mirmers. These hiph-quality, 1.2-m mirrors eventually will direct Nova's $20^{\circ}$ lare $174-\mathrm{cm}$ diam ] henms for a few billionths of a secoud to a tiay pellet containine thermomerkar fuel (dewerion an tritium). Kxplosive bblation of the outer layers of flue fuet petlet will drise an implosion thr, is expecied to compres the forl to a thousendth or less of its original volume and heat it to thermmuclear-ignition temperutures.

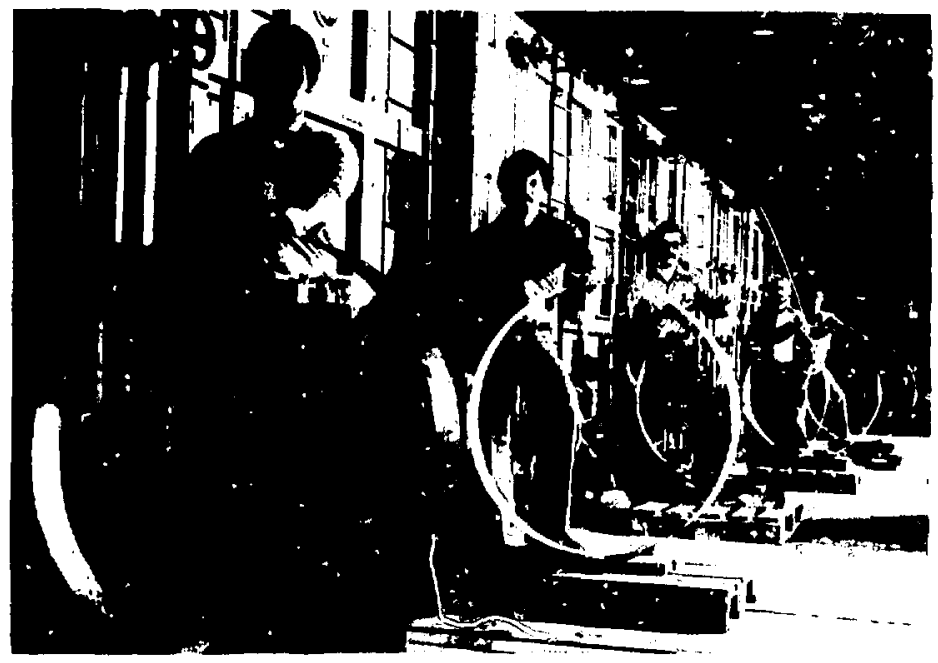

As atr example of how our new dose estimates affect the interpretation of atomic bomb survivor data, leukemia mortality data distributed according to the earlier dosimetry showed strong differences between the two bombed cities, suggesting large values of neutron RBE (reliative biological effectiveness), whertas the same mortality data distributed with the new dosimetry show no discernable differences between the two cities.

\section{Inertial Confinement Fusion}

The energy of a modern nuclear weapon is in large part the encrgy of thermonuclear fusion. One way of producing and studying fusion reactions and relitled physies in a more controlled environment is to bring at tiny deuteriumtritium (D-T) fuel pellet to very high temperatures and densities in such a short time that the thermonuclear fuel will ignite and burn before the compressed core disassembles. This technique, known as inertial ennfinement. relies upon a exiver (e.g.. a laser) to deliver the extremely high-power. short-duration burst of energy required. ${ }^{1.2}$

Inertial confinement fusion (ICF) has potential for civil applications, main!y in the production of electricity, and military applications directed toward obtaining 
data on nuclear weapons physics and creating a source of riediation to sinulate the effects of nucleas weapons on military hardware without having to conduct an ictuall nuclear test.

A power-producing fusion reactor would require lasers that deliver up to 10 pulses per second. eiach pulse capible of imploding a D-T tarect 101000 or more times the density of liquid hydregen and igniting a thernonuclear reaction that releises more than 100 tinies as much energy as the latser delivers to the target. Our Nova laser system (Fig. 4), now under construction and scheduled for con)pletion in the mid 1980s, is expected to deliver (in single pulses) 200 to $300 \mathrm{~kJ}$ of $1.06-\mu \mathrm{m}$ light or $14010200 \mathrm{k} . \mathrm{l}$ of $0.35-$ and $0.53-\mu \mathrm{m}$ light to compress its fuel capsules to 1000 times liquid density and ignite a thermonuclear reaction that releases about as much energy as the laser delivers to the larget. Although the Nova laser represents a significinnt step toward a fusion power reactor. that goal is still a distant one.

During 1980, our Shiva laser system. operating : 316 to $8 \mathrm{~kJ}$ in single 500 - to 800-ps pulses (with 1.06- $\mu \mathrm{m}$ isfrared light), successfully imploded specially designed D-T fuel capsules to more than II ' imes the density of liquid hydrogen (in excellent agreement with preshot calculations). Both the density attained and the agreement with calculations are significant as indications of our progress.

Perhaps even more significant was our demonstration on the Argus laser that we could convert $1.06-\mu \mathrm{m}$ light into $0.53-$ and $0.36-\mu \mathrm{m}$ light (green and ultraviolet. respectively) at efficiencies of $75 \%$ and our experimental confirmation of excellent laser-plasma coupling at these shorter wavelengths. Figure 5 shows the significant theuretical and observed increase in the absorption of laser radiation at 0.53 and $0.36 \mu \mathrm{m}$ and the equally dramatic change in the soft- $x$-ray conversion efficiency. Figure 6 shows the resulting many-orders-of-magnitude reduction in hot-electron and superthermal-x-ray production.

These results indicate that the implosion-drit ing conditions in targets ir:adiated with green or ultraviolet light will be significantly better than those in

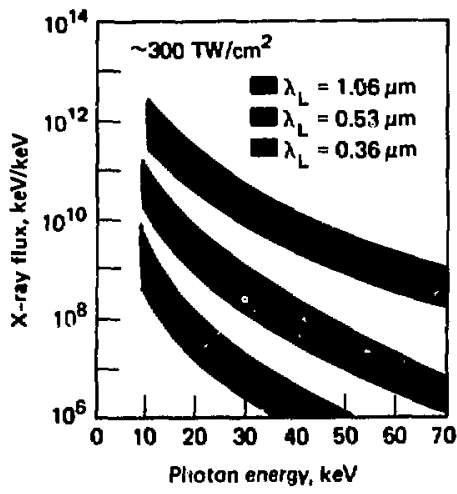

Fig. 6

Smperternal x-rov spectrn, extending far keyond the thermal x-ray apectum normally asocialed with a plasma at the measered temperature, observed in ir distis-

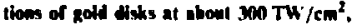
abow the intensity reyuired to drive future tangets to knition. Hef electrons. of which the nerthermal $x$ rays are evidence, inerfere with the inplosion by pewelrating the fuel pellet and pretheatias the fuel. That we are alde to reduce this hor-eiectrom pretient by e faclor of almoat ID (WW] (by changing frem infrared light to ultraviolet) has profownd and very powtive implicalions for the amount of compression to be expected frum Nova tarnet Irn. Viations.

\section{Results indicate that the implosion-driving conditions in targets irradiated with green or ultraviolet light will be significantly better than those in the same target irradiated with infrared light.}

the same target irradiated with infrared light. The inward-directed forces will be larger, and the stiffening effects, which tend to make the capsule resist implosion (e.g., preheating by energetic electrons), will be smaller. 


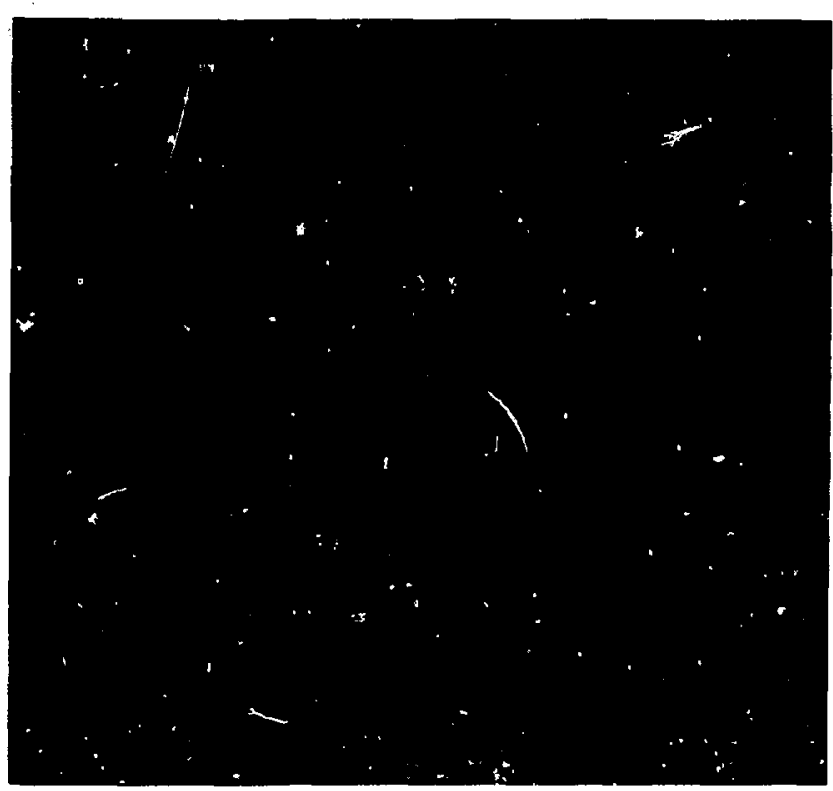

A screen display from JANUS, ail interactive combat simulator potentially capable of encompassing an entire Corps operation, showing the disposition of the Blue forces (colored symbols) near the confluence of two rivers. JANUS offers three unique feacures that make its simulations more realistic and britievable than those of previous models. It gives players pushbutton access to difierent levels of resolufion, ensbling them to view the entire sweep of an attack or to soncentrate on suct. details as individual tank battles. It achieves this capability party ly using veriable-size zoning : d partly by treating units '" mas.te' most of the time. Only when units are engaged in combat does it resolve them into their component subunits for shot-by-shot resolution of the conflict. It Also provides for difterent levels of command, glving lower ranks restricted but detailed view and reserving the broader picture for the higher ecthelons.

\section{JANUS}

JANUS is a greatly imp:oved two-sided interactive combat-simulation code for modeling an integrated battlefield.

Previous computer models. simulations. and games have had limited success in port resying the real prohlems of combst command. As a result. many users and decision-makers have been understandably reluctant to accept their recommendations.

Three key techniques implemented in JANUS during the past year, together with the use of real-time dynamic color graphics of high resolution (figure), have coniributed to a high level of acceptance of this code. The first of the new techniques involves terrain resolution-mapping a battlefield in enough detail to show individual tank encounters without overwhelming the computer with data. The previous solution was to use a hierarchy of models, ranging from fine detail for tank battles to coarse mapping for ICBM targeting. However, this raised the problem of linking the different models in a credible interactive mode. Our solution in JANUS is a hierarchy of terrains, all part of the same model. The player has push-button selection of several resolution levels, with a small grid size limited to the area of the tank battle.

Another problem that has plagued previous models is the aggregation and disuggregation of units-how to account for attrition during a battle and for the linking of two under-strength units into one. It is ulmost impossihle (because of memory constraints) to use il computer to follow the detailed history of each tank and artillery piece in an army throughout a prolonged battle. However, when these weapons systems are traveling, resting, or waiting, they have no essential impact on the overall outcome. It is cnly when they are actually engaged in combat that they must be followed.

Therefore, in JANUS, all the tanks in a battalion move together in a specified formation until they are engaged. At that point, the unit separates into its subunits, and the results of the conflict are assessed. When the battle is over, the surviving subunits regroup and may be combined with other units, freeing additional computer memory.

The third areid of improvement in JANUS is in the hierarchy of command. A captain's or a major's view of a battle is very different from that of a general Thus, different views should be (and are, in JANUS) provided, with work stations of different scope and resolution-the fine detail for the lower command echelons and the broad view for the high command. We are experimenting with personal-size microcomputers for the latter stations.

Our development of JANUS has attractcd wide interest from both the Army and the Air Force. The Army Training and Doctrine Command recently assigned two ofticers permanently to participate in further development. The potential applications range from officer training to evaluation of the war plans of forces stationed in Europe. 
Furthermore, data taken in the course of these experiments confirm the scaling relationship from earlier experiments and increase confidence in our ability to predict conditions in laser-driven target implosions. However, the most importunt result of these experiments is that this confirmation of scaling allows us to predict with considerable confidence that targets irradiated at full Nova energies in green or ultraviolet light will achieve the thermonuciear-ignition threshold and possibly attuin the scientific break-even point.

Other significunt accomplishments in 1980 include:

- Demonstration that we can use flash $x$ rays to photograph the imploding targets.

- Demonstration that we can obtain shock compressions to $5 \mathrm{TPa}$ in gold targets by laser irradiation (potentially valuable in equation-of-state studies). ${ }^{3}$

- Achicvement of essentially equivalent performance by optimization of the design of JCF targets for both heavy ion and laser drivers.

- Demonstration of target-sphere coating techniques involving molecular beams and electrostatic levitators, potentially capable of mass producing target spheres. 5

- Production of target-quality glass shells coated with layers of metal and polymer and stepped plastic hemishells for doublc-shs!! : : iscts.

- Fabrication of fuel-filled glass target spheres containing about $1 \%$ of bromine, with which we can make direct measurements of fuel compression.

- Successful cooling of fully assembled double-shell targets loaded with D-T fuel to the temperature of liquid helium.

- Demonstration that we can make optical components with graded refractive indices that will exceed the damageresistance needed for surviving 200- to 300-kJ pulses of infrared, green, or ult raviolet light from the Nova laser system. ${ }^{3}$

- Completion of prototypes of most of the Nova hardware, including final packaging of the basic short-pulse oscillator.

- Development of plastic debris shields for Nova that distort the transmitted light

\section{Targets irradiated at full Nova energies in green or ultraviolet light . . . will . . . achieve the thermonuclear-ignition threshold.}

wavefront by less than $1 / 4$ wavelength. 1

- Demonstration of a Raman-Sijkes

pulse compressor that coilcentratcs $70 \%$ of the energy of a long pulse of light from a krypton fluoride laser into a very short pulse appropriate for driving the implosion of a fusion target.

- Completion of fluid-dynamic and full-system stress analyses of HYLIFE, our liquid-lithium-lined reactor-chamber concep! for electric-power generition. ${ }^{6}$

\section{Special Isotope Separation}

The Office of Nuclear Materials Production is funding a special isotope separation program to investigate an array of laser techniques for isotope separation of special nuclear materials. Two elements, plutonium and tritium, are currently under investigation as candidates for laser-induced isotope separation processes.

\section{Defense Projects (DOD)}

LLNL conducts a variety of projects for the Department of Defense. The explosives, hydrodynamics, and warhead engineering capabilities we have developed for the nuclear esplosives. program place us in a unique position to help the DOD improve the performance of nonnuclear weapons systems. Also, our fusion energy research has given us facilities and expertise in generating charged particle beams, which someday may have military applications.

\section{Nonnuclear Ordnance}

Under the auspices of the Joint Cruise Missile Project Office of the Department of Defense, we are currently developing the VAM-93, a miniature bomb designed 


\section{Fig. 7}

Artict's cunception of a cruise misite attack ew an sirflek with VAM-93 cratering stimovitions. As the wisht hies hlowg the airsrip, it ejects growps of warheads at intervals. They descend by parachete and detonate on impact. Fach warked consists of a shaped charge that punches a small hole in the concrete, s velocity angmentor that drives the main part of the warhend under the concrete, and the main charge (insensitive nigh explosives, which schleves maxiaum upheaval damage by detonating only afler it hay penetrated the concrete.

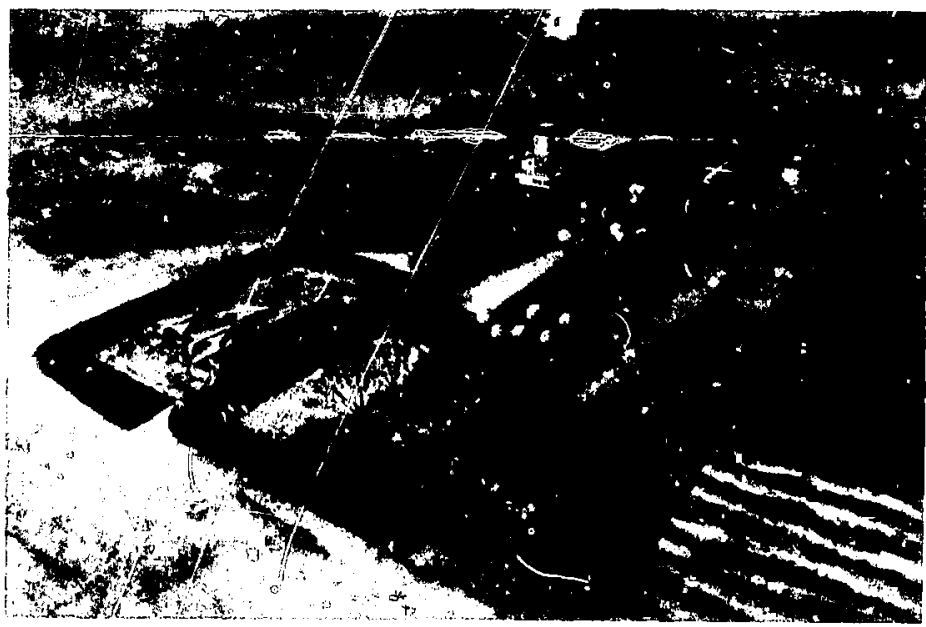

\section{The VAM-93 is a miniature bomb designed to break up Warsaw-Pact airfield runways in the event of a Soviet attack in Central Europe.}

to break up Warsaw-Pact airfield runways in the event of a Soviet attack in Central Europe. One medium-range air-to-surface missile could curry a great many of these warheads and distribute them along a runway in a single low-level pass (Fig. 7). The VAM- 93 warhead is $35 \mathrm{~cm}$ long, descends by parachute, and has three stages that function separately:

- A shaped charge in front that blows a small hole in the runway concrete, clearing the way for the main charge.

- A velocity augmentor that drives the main charge under the concrete for optimum performance.

- A naain charge canister loajed with the explosive T'ATB that survives impact and detonates only after it has penetrated the runway, causing severe upheaval damage.

We have successfully fired the three stages of this warhead, singly and in combinations, in both static and dynamic tests.

Our current design efforts include studies to improve the performance of the forward shaped charge, to reduce the case weight, and to increase the explosive energy of the main charge. We plan to test an optimized version of the VAM-93 this fall in live drops from a $T-33$ aircraft against a simulated runway section.

The successful performance of the VAM-93 has stimulated design studies of three larger versions: the VAM-114 and the VAM-125 for delivery by either a cruise missile or an aircraft and the VAM165 for use as a hand-emplaced cratering munition.

Since October 1979, we have been engaged in a program for the Ballistic Missile Defense Advanced Technology Center to develop a three-dimensional Eulerian hydrocode (JOY) that can model hypervelocity impacts of shrapnel-like material on incoming ballistic missiles.

To fulfill its mission, the JOY computer code must be able to deal with strengthof-materials questions and the shock initiation of high explosives. It must also incorporate a method of transferring information to the structural-analysis code DYNA3D. We intend to use JOY to model the initial phases of impact (where stress levels are high and material motion is complicated) and then to let DYNA3D handle the much slower structura] response. Most of the algorithms used in 
JOY are based on techniques that have neen well te:ted over several years.

A valuable extension of this work was a series of two-dimensional impact calculations embodying the first significant use at LLNL of elastic-plastic now modeling in an Eulerian format. The successful completion of these calculations greatly im. proved our modeling capability.

The JoY code uses a Cartesian coordinate system within which grid planes can he progranmed to move to perform an internal rezoning. It is a multifluid code with no fundumental linit on the number of regions that can be carried. It has second-order aceuracy in the advection of mass, energy, and momentum. The standard analytic equation-of-state forms are all available.

JOY contains a variable-yield strengthof-materials model that treats workhardening. pressure-hardening, thermal softening, and melting. Muicerial-failure models include both tensile and duciile failure. JOY also includes a proven HE shock-ini :ion model, and it possesses a versatile mesh generator capable of building three-dimensional figures from arbitrary planes, spheres, and conic sections. However, the graphics capability is still minimal.

JOY was written in a format consistent with standard FORTRAN usage so that it might be used on computers elsewhere. Within this portability constraint, however, it was designed for maximum efficiency on the Cray computer, making heavy use of the Cray's automatic vectorization capability and its ability to handle short vectors efficiently.

The speed of the code is quite problemdependent. Observed speeds range from 25 to $70 \mu \mathrm{s} / z o n e$ cycle for pure hydrodynamic modeling and from 30 to $90 \mu \mathrm{s} / z 0 n e$ cycle when the elastic-plastic model is active. At the outset, we thought that computational speed would be the crucial consideration. Instead, we have found that the three-dimensional modeling capability is limited by the finite cupacity of the computers and the resulting zoning constraints.

In October 1980, following a long shakedown period during which we checked out the code, added production features, and designed the link to

\section{JOY can model hypervelocity impacts of shrapnel-like material on incoming ballistic missiles.}




\section{Fig. 8}

Possibe apelicutions of charged-parriclebean sccelerators, plotted in terms of the required beam energy and charge per pulse (current times pulse length). The Experimental Test Accelerator (ETA) and the Advanced Test Accelerator (ATA) occupy strategic locations where the requirements of several scientific and technological applications overiap.

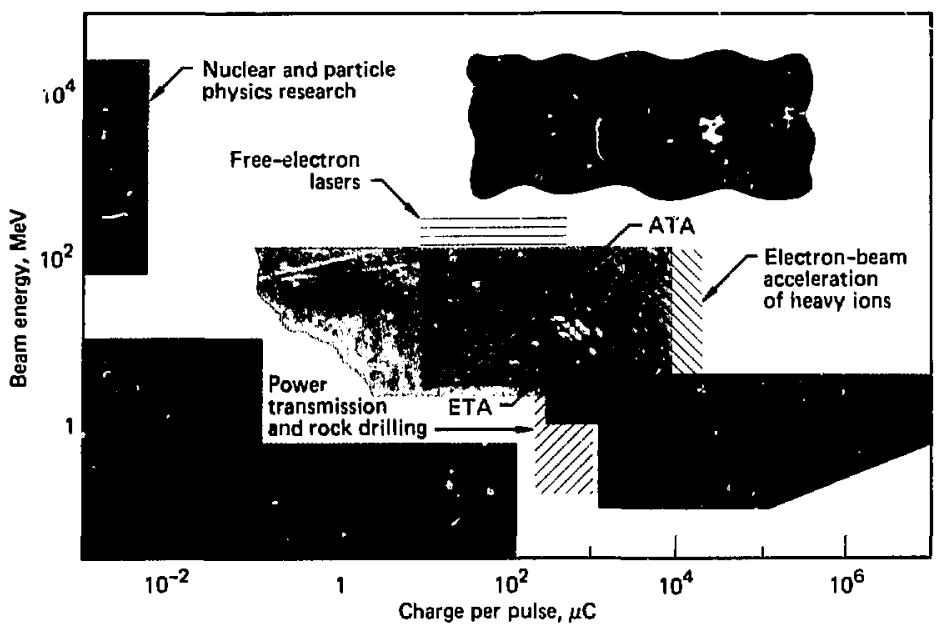

DYNA3D, the code was put to work on si nple impact studies. By the end of the year, JOY was making a substantial contribution to our programmatic studies.

\section{Charged-Particle-Beam Research}

Since June 1979, we have been operating an experimental test accelerator (ETA) based on the linear-magneticinduction principle and incorporating other equipment and techniques developed for our Astron program. ${ }^{7}$ This accelerator delivers 30-ns 10-kA pulses of 5-MeV electrons, with up is five pulses in a burst and an interval between pulses as short as $1 \mathrm{~ms}$. It has served as a technology test bed for the design of a larger version, the Advanced Test Accelerator (ATA), which will be capable of producing $5 \mathrm{U}-\mathrm{MeV}$ beams at the same currents and pulse rates. ATA construction is funded by the Defense Advanced Research Projects Agency (DARPA), with the Naval Surface Weapons Center as direct agent.

The ATA will be used to study the propagation of intense electron beams in air and the interactions of such beams with various materials. The potential military applications of sucb phenomena (in missile defense, for example) are of great interest (Fig. 8).
The essential difference between the ETA and the ATA is in the number of accelerator modules ( 10 for ETA; 195 for ATA), each of which increases the beam energy by $0.25 \mathrm{MeV}$. The added complexity of the ATA places great demands on hardware reliability and lifetime. The added length also makes accelerator instabilities more important and focusing requirentents far more stringent.

\section{Summary}

During the past year, the emphasis in the nuclear weapons program has been on the development of new weapons, with planning toward a more vigorous experimental advanced development program nex1 year. Our testing group has continued to develop and incorporate new instruments and techniques to expedite the measurement of significant explosion phenomena. We have done engineering design work on various warheads and have brought several to the production phase. In addition we have developed and applied JANUS, a greatly improved twosided interactive combat-simulation code suitable for use in officer training and in evaluations of the war plans of forces stationed in Europe.

Inertial confinement fusion is even now useful for some kinds of weapons 
research, and its usefulness will grow as we increase the output of energy of tiny D-T targets imploded by our large lasers. The Noya laser system, scheduled to be completed in the mid-1980s, is expected to demonstrate thermonuclear ignition and may also demonstrate energy break-even conditions.

During the past year, nonnuclear ordnance work has included the development of a three-dimensional hydrocode (JOY) that models hypervelocity impacts of shrapnel-lıke material on incoming ballistic missiles and the development of the VAM-93, a miniature bomb designed to break up airfield runways.

Construction of an Advanced Test Accelerator (ATA) is continuing. The ATA will be used to study the propagation of intense electron beams in air and the interactions of such beams with various materials. The potential military applications of such phenomena are of great interest.

Key Words: Adranced Test Aceelerutor: beam weupons: Experimentul Tost Accelerutor: ComputerAided Design and Drafting: Drone: DYNA3D: gascous tracers: ICF; inerlial confinement fusion: JANUS: JOY: laser fusion: Nova laser system; sejsmic-renecion mapping: Shiva laser system: VAM-93: VAM-114: YAM-165,

\section{Notes and Reforences:}

I. "The Nova Lidser Fusion Fucility." Energy and Technology Review, UCRL-52000-81-12. Decemher 1980, p. 1.

2. A comprehensive review of laser lusion developments up to mid-1977 was given in Energy and Technolug! Revien: UCRL-52000-77-8. Aup̣ust 1977.

3. "Litser-Driven Shack-Wave Experiments," Energy and Technolngy Review. UCRL-5200079-10, October 1979, p. I8.

4. "Heavy-Ion-Driven Fusion," Energy and Trcholog, Raview, UCRL-52000-80-3, March 1980. p. 16.

5. "Ultrasmooth Coulings for Microsphers Turgets," Energy' and Technology Review. UCRL-52000-80-4. April 1980, p. 20.

6. "The HYLIFE Concept: Electricity from Laser Fusion," Energy and Technology Review. UCRL-52000-79-10, October 1979, p. 8.

7. The experimental test accelerator (ETA) was discussed in Energy and Technology Review, UCRL-52000-79-9. September 1979, D. 16. 


\section{LLNL is applying its unique experience and capabilities to a variety of projects that will help the nation meet its energy needs in an environ- mentally acceptable manner.}

LLNL projects aimed at helping the nattion neet its energy needs go hand ia hand with reseurch into the sources of energy. related pollutants and their effects on plants, animals, and humans. The largest of the entrgy projects is our magnetic fusion energy program, with its longrange goal of developing the technology for a fusion power plant. Our atomic vapor laser isotope separation (AVLIS) program aims to demonstrate more efficient, more flexible, and less costly means of producing enriched uranium for nuclear energy. Also significant is the aluminum-air battery development (part of our transportation systems research program). which holds out the promise of an electric aitomotive propulsion sy stem that would be independent of petroleum fuels and would provide a vehicle with performance comprarable to that of todily's automobiles.

Studies of the sources, methods of transport, and effects of energy-related pollutants (both nuclear and nonnuclear) are progressing under the direction of our biomedical and environmental research program, and we are participating in several Nuclear Regulatory Commission projects, including two foreign reactorsafety studies.

\section{Energy}

With the increasing awareness that fossil energy sources are finite, there is heightened interest in the development of alternatives. Several LLNL programs are making significant contributions in this area. Our magnetic fusion energy (MFE) program, which seeks to harness the ulmost limitless energy of thermonuclear fusion, completed its tandem mirror experiment (TMX) last year, realizing a major breakthrough in magnetic confinement of fusion plasmas. Within the last year, our primary technology for laser isotope separation has been brought to the development stage where we can move into a major engineering effort to develop equipment that can be utilized in a production environment. Our aluminumair battery program demonstrated both that the very promising electrochemistry of small test cells is definitely amenable to scale-up and that the cell stack and crystallizer work logether as expected. Piogress in these three programs is described below.

\section{Magnetic Fusion Energy}

Thermonuclear fusion, the process by which two light nuclei combine into one at extremely high temperatures (releasing energy as they do), is in many ways an ideal solution to the energy problem. Successful development of a fusion reactor would give us practical access to fuels-deuterium (from water) and lithium-that will last for millennia.

However, producing and controlling fusion reactions is difficult. They occur only at hundred-million-degree temperatures (as in the sun or in a hydrogen bomb). To produce such temperatures in a power plant and contain the fuel long enough to extract useful energy is beyond the capability of existing technology.

Oive possible solution to the problem is to rely upon specially shaped magnetic fields to confine the fuel (hot, ionized 


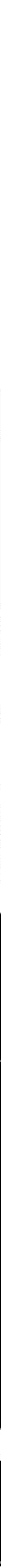




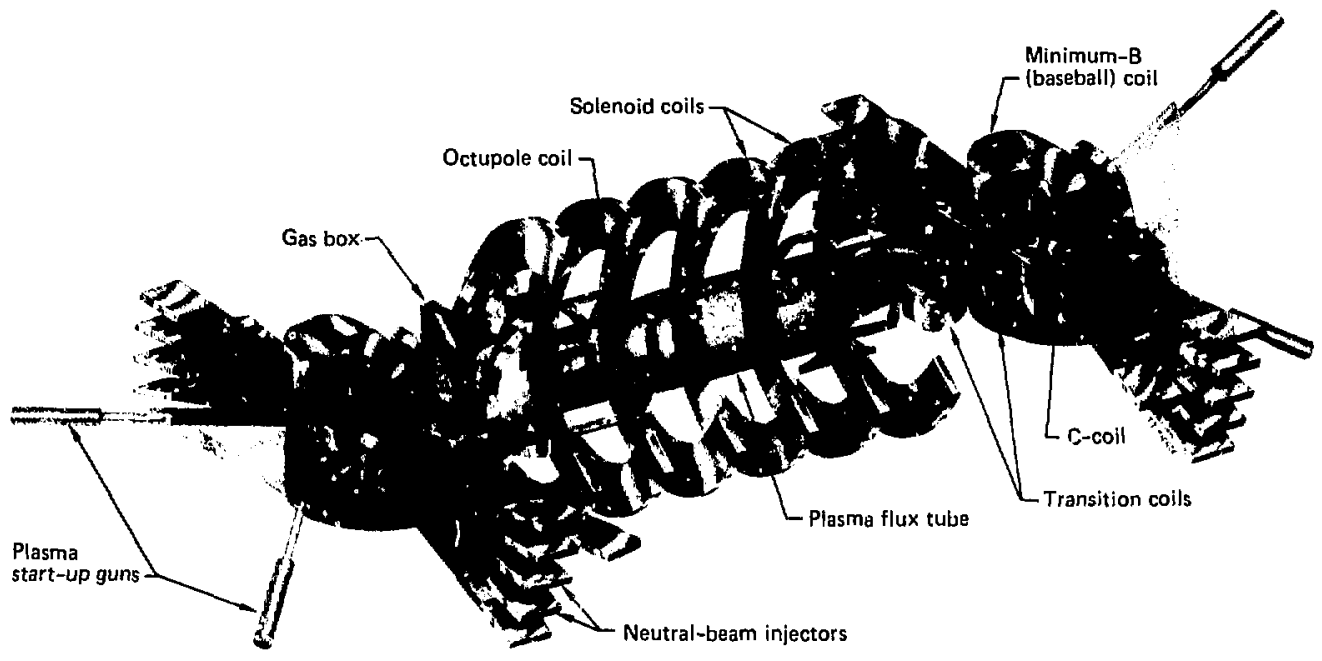

\section{Fig. 1}

\begin{abstract}
A simplified cutaway drawing of our tandem mirror experiment (TMX). The TMX apparatus consisss of a series of circular magnets (solenoid coils) in the sentral region capped at both ends by minimum-B (baseball) magnets. We use plasma guns at the end of the machine to create a plasma initially. Then, to heat the plasma, we inject energetic beams of deuterium atoms (neutral beams) from outside. The solenoid section provides a large reservoir of heoted ions, and the minimun- $B$ magnets provide an electrostatic barrier that keeps the ions from leaking out the ends. The entire apparatus is enclosed in a vacuum vessel, which excludes conlaminating gas molecules that would coo' the plasma. The auxiliary plasme-shaping coils (C-coils, transition coils, and octupole coils) make a smooth transition between the certral magnetic Field and the end-cell fields. The minimum-B magnets are turned so as to orient the fan-shaped ends of the plasma nux tube at right angles to each other, enhancing confinement.
\end{abstract}

gases known as plasmas), while heating it to rusion temperatures by some external means. This approach is followed by our MFE program. ${ }^{1-3}$ Another approach, inertial confinement fusion, is described on p. 12 of this issue.

Magnetic fusion development has not yet reached the point where we can specify the exact form of a fusion power plant, but recently we have made great strides toward that goal.

During 1980, the MFE program's Tandem Mirror Experiment ${ }^{1}$ completed a three-phase experimental program begun in late 197x. After an eight-month checkout period and a six-month initial operating period, it advanced into a tenmonth experimental phase in which we corroborated the initial results and carried out many detailed physics investigations. These experiments confirmed our expectaiions based on theory; the tandem mirror device, with minimum-B magnetic fields plugging the ends of a straight solenoid field (Fig. 1), confines the hot plasma better than any of our previous machines.

The TMX experiments vcrified that we could sustain density gradients within the plasma by means of neutral-beam injection and that the resulting electrosiatic potential gradients turn back ions that would otherwise escape from the central cell. As a result, the TMX end plugs improved confinement of the central-cell plasma by as much as a factor of nine.

We also measured the central-cell plasma potential as a function of radius and showed that the confining electrostatic potential gradient is not loculized near the axis but extends over a radius of $25 \mathrm{~cm}$. Radial and axial profile measureinents of plasma density and temperature confirm the large volume of plasma confined in the central cell. We also generated and maintained end-plug potentials exceeding $\mathrm{I} \mathrm{kV}$.

The TMX design provided a hundredfold improvement in electron-energy confinement. This came about because the end-plug plasmas were stabilized by lowenergy plasma from the central cell. The result was an effective decoupling of the plasma from the end ralls. Thus, andplug electron temperatures of $2 \mathrm{f}^{\wedge} \mathrm{eV}$ were achieved (three to four times higncr than levels reached in the past with comprable neutral-beam power). The cool end-wall plasmas had a very low density (ten thousand times lower than that in the end plug). This decoupling will be an essential feature of future high-temperature MFE machines.

Another significant accomplishment was a remarkably low central-celi 


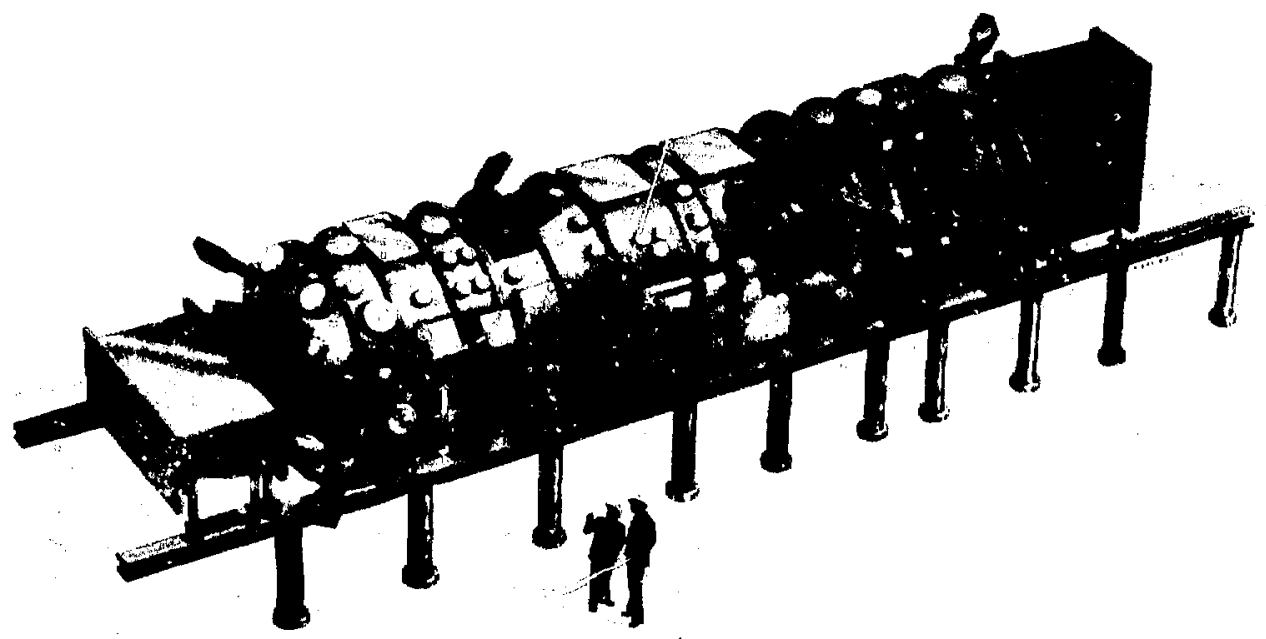

impurity level $(0.5 \%)$, which kept the power loss due to impurity radiation to less than 10\%. High-resolution spectroscopy of the impurity radiation and diamagnetic-loop measurements indicate central-cell ion temperatures of 100 to $200 \mathrm{eV}$.

The TMX diagnostic instruments ${ }^{1,4}$ provided large quantities of data over a broad spectrum of operating conditions. Comparisons between this body of data and theoretical predictions already has resulted in improved computer models for describing plasma performance over a wide range of input parameters. ${ }^{5}$ We are also developing better tools for analyzing novel magnetic configurations for plasmaconfinement stability.

The breakthrough in plasmacontainment charact tistics demonstrated in the TMX justified a complete revision of our ma:netic fusion energy development timetable. We immediately rejesigned the Mirror-Fusion Test Facility (MFTF), already $85 \%$ finished and originally scheduled for completion in 1981 , converting it from a single-mirror to a tandem-mirror configuration (MFTF-B). ${ }^{2}$ When it goes into operation in 1985, the MFTF-B may be capable of demonstrating with deuterium alone that power-break-even plasma conditions would be achieved if deuterium and tritium were both used (as they would be in an actual reactor). We also designed and began construction of an UPEraded TMX (Fig. 2), to be completed in the fall of 1981 .

The system for maintaining plasmapotential barriers that was successful in the TMX (neutral-beam injection) would, if enlarged to the size needed for a powerproducing reactor, require central magnetic fields of $17 \mathrm{~T}$ and neutral-beam injection approaching $1 \mathrm{MeV}$. It would be difficult to meet these requirements, even with advanced technology now in development. We are, therefore, investigating alternative end-plug configurations that will operate within more modest limits.

One of these alternatives is the thermalbarrier concept, which vould isolate the end-plug electrons and make it possible to
Fig. 2

The upgraded TMX machine, which features a thermal barrier in the end cells and oblique injection of neutral beams in the central cell ( $45^{\circ}$ tu the axis rather than $90^{\circ}$ ). The thermal barrier serves to isolate the end-cell electrons from those in the centrat cell and permi! them to he hexted by tuned microwaye energy (electroncyclotron-resonance heating, or ECRH). This, in turn, expedites their escape from the plasma, raising the col plasma potential boytind what would be possible with density gradierts alone. Ohlique neutralheam injection is expected to improve the mierostability of the end-cell plasmas. The size of the men in the foreground indicates the size of the machine. 


\section{Successful development of a fusion reactor would give us practical access to fuels- deuterium (from water) and lithium-that will last for millenia.}

use microwaves to heat them independently. This would produce the necessary end-plug potential gradient without such a large density gradient, reducing the inagneic field and neutral-beam-energy requirements. We will be testing this concept in the TMX Upgrade, logether with a new $45^{\circ}$ neutral-beam injection angle. which should improve the microstability of the end-plug plasma confinenent. We are also planning to apply these concepts in the MFTF-B machine.

The MFTF-B will be mesh larger and more powerful than the TMX. Whereas the TMX operated in 25.ms pulses and used winer-cooled magnets. the MFTF-B will use superconducting magnets (shown on p. 20) and 30-s neutral beams. Figure 3 indicates the sealt of this equipment and some of the details of construction.

Nearly all the equipment purchased or construcled for the MFTF will be used in the MFTF-B. This includes the 230-kV. 250-MW pulsed power subsystem, the iwenly-four 80-kV. 88-A de power subs?stems of the sustaining neut ral-beaminjector power supplies, the 10.6-m-diam vacuum vessel. the cryogenic system for liquefying. distributing. and recovering helium, and the superconducting yin-yang magnets.

The MFTF-B will use a unique. completely computerized control and diagnostic system that provides a hierarchical structure for the collection, communicalion, processing, and display of information. Much of this equipment has already been delivered and tested.

The magnetic fusion energy program is making good progress toward its goals. The MFTF-B machine, scheduled for operation in 1985, approaches the size and complexity of a fusion reactor and is expected to demonstrate break-even plasma conditions over relatively long periods (30 s).

\section{Laser Isotope Separation}

The Department of Energy, Office of Nuclear Energy, sponsors ehree advanced isotope separation programs with the goal of demonstrating more efficient, Mexible, and less costly enrichment of uranium for nuclear reactor fucl. We expect a decision $\checkmark$ thin the next year as to which advanced isotope separation technology will be 


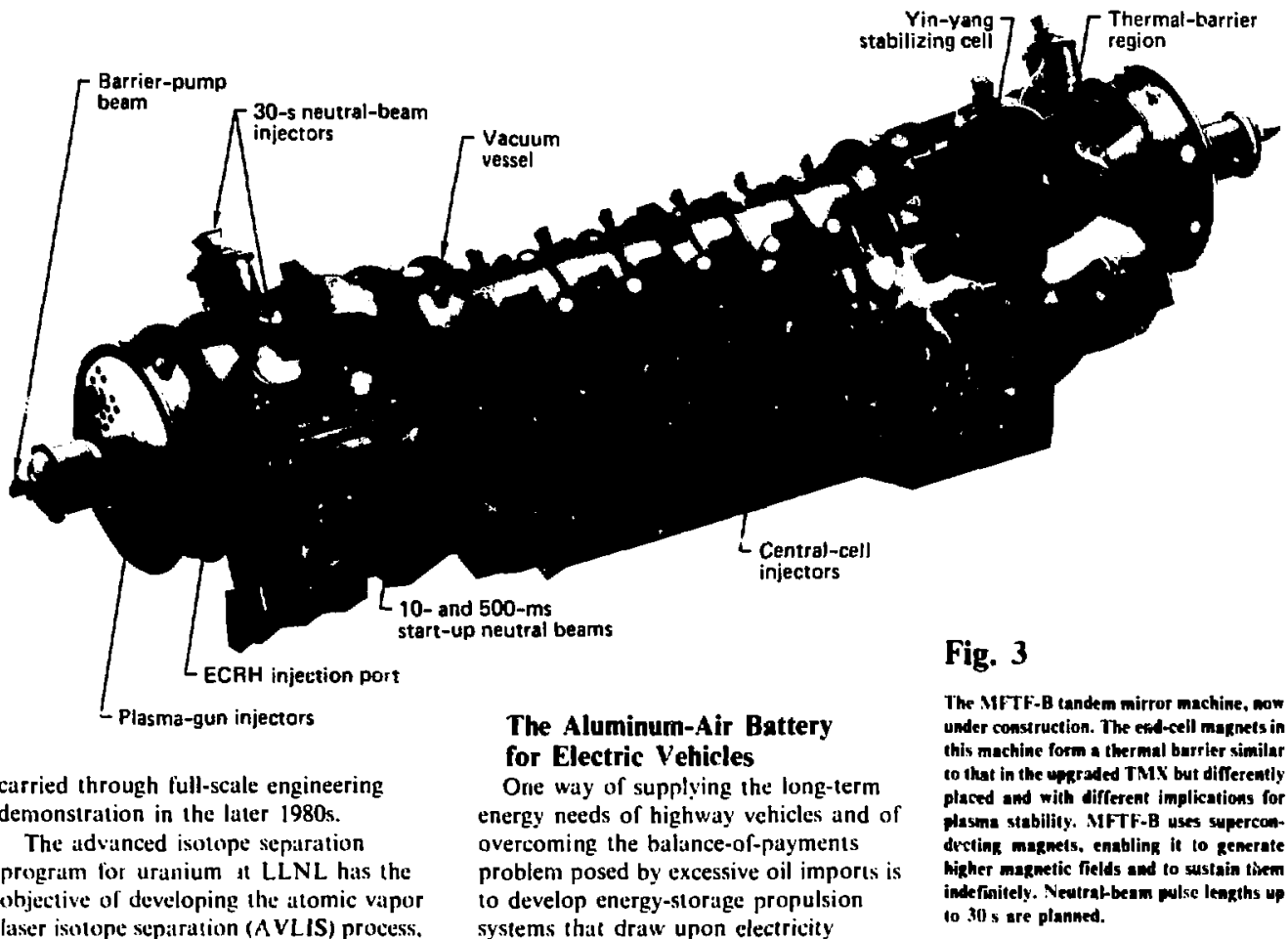

laser isotope separation (A VLIS) process. which promises a significant reduction in plant capital costs over other isotope separation processes, as well as reduced power requirements and operating costs.

LLNL's primary laser isolope technology uses copper-vapor pumped dye-lasers to selectively ionize atomic vapor by means of powerful. tunable, laser radiation. The resulting ions are sepazated from the neutral-vapor stream and collected as enriched product. In the last yeur, we have brought this technology to the point where we can move into a major engineering effort to develop production equipment.

Existing integrated research facilities for lasers and vaporizers, developed and operated over the past several years, will continue to operate and provide further refinement and improvement in our basic understanding of this important new process technology.

\section{The Aluminum-Air Battery for Electric Vehicles} energy needs of highway vehicles and of overcoming the balance-of-payments problem posed by excessive oil imports is systems that draw upon electricity produced from nonpetroleum fuels. Electrically rechargable batteries may sonieday power short-range electric vehicles for specialty markets. However, if we are to build a competitive, general-purpose electric vehicle. we must look beyond conventional batteries to such concepts as that of the aluminum-air battery. 6

LLNL is the lead laborator, for DOE development of metal-air batteries. 7 ne aluminum-air battery is one of the key elements in that program. It is expected to provide an electric vehicle with the range, acceleration, and rapid-rc!eeling capability of today's automobiles. Our role is to provide technical direction for the project a.ıd to conduct research in certain areas critical to the integration of the diverse technologies involved. Much of the development work is carried out by industrial subcontractors with unique expertise in certain problem areas.

\section{Fig. 3}

The MFTF-B tandem mirror machine, now under construction. The ewd-cell matents in to that in the urisraded TMIX but differently placed and with different implications for Flasma stability. MIFTF-B uses supercondecting magnets. enabling it to zemerate gher magnetic fields and to sustain them 10 30 s are planned. 


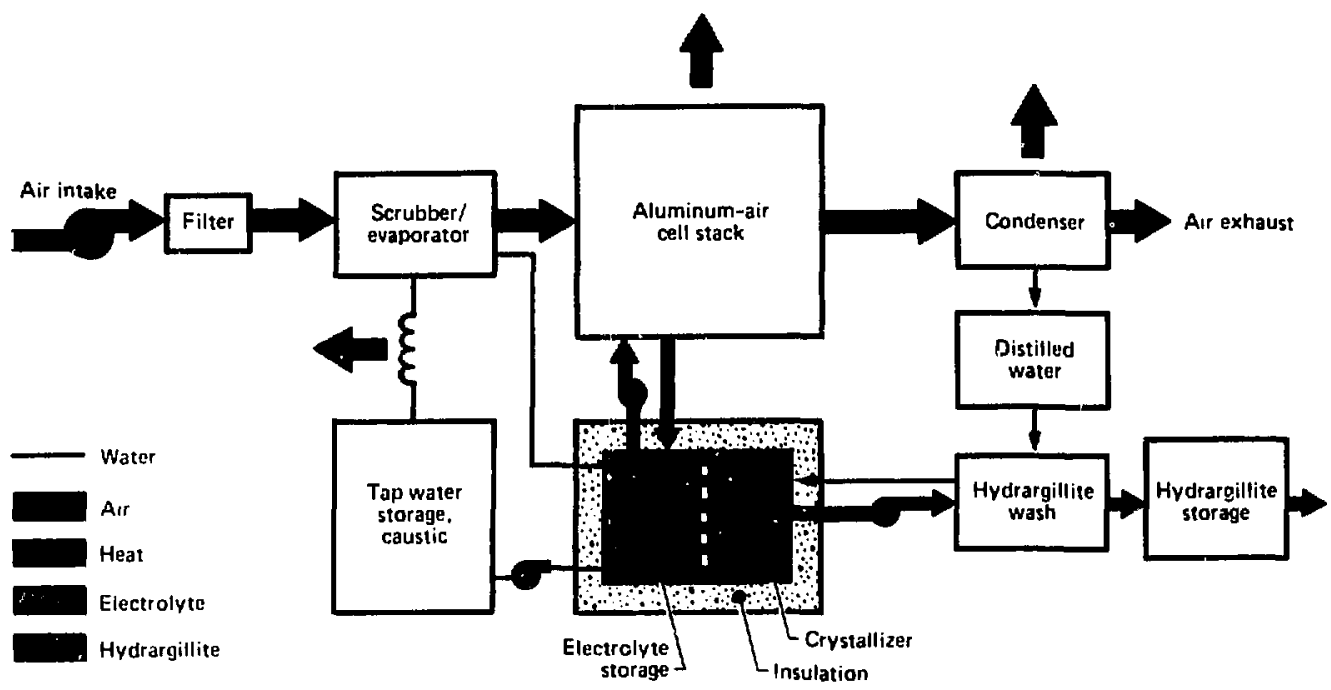

\section{Fig. 4}

Diagram of a cumplete aluminum-air hatters intem. Fleceleulyte is circulated he. incen the sell stack and the crovellizer whele the hy drargillite reactien product con he crobaltiesed. The hodrargillite is then nathed, partialls drained, and stured. - When remosed from the sysem. it will be recocled til prodese more aluminum and peribli aluminum fuel plates. I tir enters the vosem, is wruhted In remose carhon dioxide and road dirt, seturated with natcr. and. finalls. reacted in the cell stack. Hater is cundtrusted from the eviting air. which is then sented ot) the semusphere. The condenoer supplien divtilled mater for washing the hedrargillite, and ihat nuter wheryuenils when ithe crevallifer ahre is hecomen a reactant. Circulating lup nuter ale transfers mat from the electrolyte to the atmosphere and mats the incoming air.
The owerall aluminum-air batlers ststem for a private highwal vehicle is diagrammed in Fig. 4. In addition to the cell stack and crystallizer. components ats provided to remove carbon dioxide and road dirt from the incoming air stratam and to wash. drain, and store the hydrargillite (the end product of the reatetion in the aluminum-ilir battery). Tap water is evaporated into the incoming air, and a portion is then condensed from the exhilust of the cell statck to provide for the chemical retetion and to remove soluble citustic impurities from the bydrargillite. The battery is recharged by the addition of tap water (every $400 \mathrm{~km}$. or $250 \mathrm{mi}$ ) and fresi) aluminum plates (att intervals of 1600 to $4800 \mathrm{~km}$, or 1000 to $3000 \mathrm{mi}$ ).

We recently finished lesting a number of 25-10 50- $\mathrm{-m}^{2}$ (4-10 8-in. $\left.{ }^{2}\right)$ single power cells. The normal operating voltage of these cells ( $1.55 \mathrm{~V}$ at $\left.2 \mathrm{kA} / \mathrm{m}^{2}\right)$ is $30^{\mathrm{r}}$, greater thitn that achieved at the start of the battery development program. and the peak power of $6.3 \mathrm{~kW} / \mathrm{m}^{2}$ is twice that originally projected for an aluminum-air power cell. This year, we also tested fullsize $1000-\mathrm{cm}^{2}\left(1.1-\mathrm{ft}^{2}\right)$ cells with full-scale crystallizer units (used to control the electralyte concentration in the cells and to produce metallurgical-grade hydrargillite). Our results indicale that the voltige per enit electrode area in the larger cells does not differ significantly from that achicred with the small cells. While lechnic:tl problems nust yet be solved in the development of a rapidly refuelitble $1000-\mathrm{cm}^{2}$ cell, the electrochemistry appears to be amenable to scitlesup.

We currently are testing rapidly refuclable cells and shortly will begin testing muiticell stacks. Our plans cill for the demonstration of a rapidly refuelable.

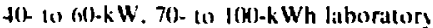
protonype in 1985 and of a battery suitable for ins'allation in al vehicle by 1987.

There are diffeult problems that must be resinlved before we can fully establish the technieal and economic viability of the aluminum-iir battery. However, successful development of the bittery would make it possible to build an electric vehicle competitive in performance and cost with internal combustion vehicles powered by synthetic liquid fueis derived from coal.

\section{Environment}

Unique LLNL experience and $c_{a}$ abilities contributs to investigations of a variety of environmental and biomedical 
problems. We have developed techniques for use in studies of the effects on human cells of pollutants in the environment-for example, the production of cancer-related gente mutations. We are analyzing environmental inpact and required control technologics in connection wh future geothermal deselopment in California's Inuperial Valley. We are also evaluating the feasibility of safe and reliable short-lerm slorage of spent commercial-reactor-fucl assemblics at al realistic repository depth in common granite rock in Nevada. Our Atmospheric Rolease Advisory Capability (ARAC) has enabled us to provide alceurate and timely information about the probable effects of atmospheric release of radioactive and other toxic materials. Below, we describe bricfly work that is representative of LLNL's efforts in these areas.

\section{Biomedical Sciences}

The major emphasis in our biomedical program is on sludies of genetic injury and cancer-related biology in humans. We continue to emphasize now cytometry. a powerful new way to analyze and separale cells al high speed and resolution. In the past sear. we have learned how to prepare human blood samples for chromosome analysis by llow cytumetry: nou, we can resolve 20 of the 24 human thromosumes automatically and routinely. This year, working with scientists at the University of California at San Francisco (UCSF). we used chromosomal sorting done with fow eytometry to determine that the gene for producing insulin is locited on the short arm of the human chromosome 11.

We are also using fow cylometry for a human somatic mutation assay to detect the rare (one in 10 million) red blood cells that contain mutant sickle hemoglobin. This year, we initiated a small clinical trial to compare the incidence of sickle hemoglobin in normal individuals with that of patients undergoing cancer chemotharapy.

The feasibility of using flow cytometry for automated cancer screening of Paptest specimens is now accepted, and the approuch is being evaluated in a series of pilot studies. In the first of these studies, specimens obtais.ed from 74 women who were clinic patients at UCSF were

\section{With flow cytometry, we can resolve 20 of the 24 human chromosomes automatically and routinely.}

screetied for ahmormal (dysplastic and cancerous and normal cervical specimens. The How sytomety method yictded less than $10 \%$ false negative and 32 r: false positive reports. We hope to reduce the proportion of false positives in a larger study zou under way that uses specimens from a groun of normil nonhospitalized woman. LLNL volunteers.

We are continuing lo evaluate abnormal sperm morphology in man as an im. portant indicator of genetic darlage. Two approaches thit show great promise are

- Mow cycometry using slit illumination and image analysis using scanning microscopy. In addition, this year we significantly improved a test that eslimutes the number of $Y$ ehromosomes per humlan sperm.

Studies of sister thromatid exchange in blood cells of LLNL employees were begun this yeits with the objective of identifying and quantifying personal factors that might affect results of this important genetic assay. $\Lambda$ clear dose-related effect of cigarette smoking has already been found. Meanwhile, laborator: studies are making rapid progress in determining the mechanism and significance of sister chromatid exchange.

Recently, we initiated a restudy of the health-effects data from Hiroshima and Nagasaki in the light of dosimetry calculalions done by LLNL under weapons program sponsorship (see p. 9). Thete new calculations indicate that the gammaray component and tolal dose were lower in Nagasaki and substantially higher in Hiroshima thin previously believed, while the neutron component was much lower 
in both cities. The data accumulated by the Atomic Bomb Casualty Commission and its successor, the Radiation Effects

Research Foundation, are being reevaluated to determine the effect of the new dose calculations on values for the relative biological effectiveness of neutrons and on the risk coefficients of radiation-induced cancer and chromosome dilmige, and the consequences for radiation protection.

\section{Environmental Sciences}

A significant fraction of our environmental effort in the past few vears has been devoted to assessment of the impact of geothermal resource development. These activities are nearing completion. We designed a computer model to identify the land-use constraints and conflicts posed by geothermal resource development in The Geysers region of California. This model can be user to evaluate sites. areas, or regions for geothermal development or for any land-intensive energy development. Our detailed analysis of the environmental impact and control technologies associated with future geothermal development in California's Imperial Valley provides necessary information for developing this resource in an environmentally sound munner.

A major phase of our continuing activities in assessing the radiological condition of the Marshall Islands ended this year as we completed a study of the radiological consequences of resettling Bikini and Enewetak Atolls. This study will provide a basis for recommended resettlement scenarios that minimize radiological consequences.

Our projects relating to environmental protection require instrumentation that meets very stringent requirements. For example, many of our field studies require instruments that are portable, durable, respond rapidly, and have high sensitivity and discrimination. This year, we designed and tested a portable rapidresponse sensor for measuring the concentration of methane and ethane in the dense fogs produced by liquefied natural gus spills on water. Several of these sensors have been built for use in the LLNL Liquefied Energy Fuels dispersion tests at Cnina Lake, California.

\section{Deep Geologic Storage of Spent Reactor Fuel}

The objective of LLNL's spent-fuel test in the Climax granite at the Nevada Test Site is to evaluate the feasibility of safe and reliable short-term storage of spent commercial-reactor-fuel assemblies at a plausible repository depth in common granite, followed by retrieval of the fuel. During this five-year project, we will collect datu needed to evaluate granite as a medium for deep geologic disposal of highly radioactive reactor waste and to design such a repository in granite.

Using existing mining, engineering, and electronics technologies, we have constructed one storage drift of a hypothetical repository at the Nevada Test Site, $420 \mathrm{~m}$ below the surface in the Climax granite stock. By imposing appropriate boundary conditions, we subject the encased spent-fuel assemblies and the surrounding rock mass to the thermomechanical and radiation effects that would occur in a large-scale repository. We are also comparing in situ the effects on granite of heat alone (electrical heaters) with the effects of high-level ionizing radiation plus heat (spent fuel). We use an extensive array of instrumentation deployed at more than 600 locations to monitor the temperatures, radiation levels, stresses, and displacements occurring in the test facility.

During April and May of 1980, II canisters of spent fuel approximately 2.5 years out of the reactor core and 6 elect rically heated simulators were emplaced in the test storage drift. Monitoring of the temperatures of the spent-fuel canisters, the steel hole liners, and the surrounding rock revealed that peak canister temperatures of about $145^{\circ} \mathrm{C}$ were reached in late July and early August of 1980. The fuel canisters and hole liners are now cooling gradually, while the surrounding rock is still heating slowly. To demonstrate the feasibility of retrieving the spent-fuel assemblies from storage, we made a successful exchange of one of the spent-fuel canisters in January 1981.

Because this spent-fuel test site is the only facility in the world where high-level reactor waste is in deep geologic storage, the test has received much public attention. Emplacement of the first spent-fuel 
Table 1 Summary of ARAC responses during FY-1980.

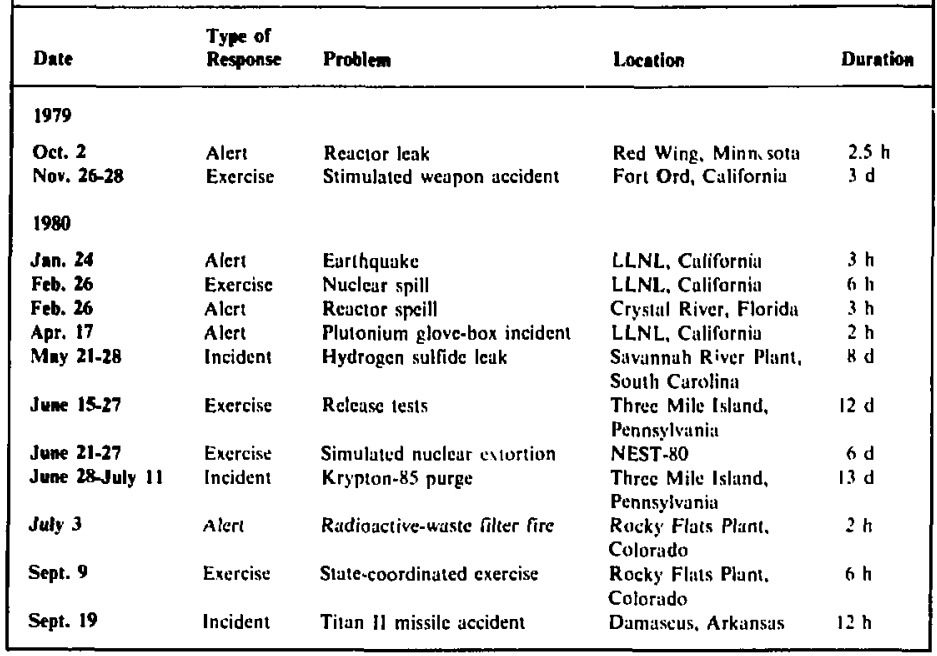

canisters was given full media coverage, and since then we have conducted more than 120 tours for approximately 1600 representatives of technical, government, and public interest groups from the U.S. and 22 foreign countries. To disseminate our engineering and scientific findings, we have published and presented 26 technical papers.

In the first year of this five-year test, we have demonstrated that spent fuel from commercial reactors can be safely and reliably encapsulated, transported, placed into, and retrieved from deep geologic media using current technologies. We have confirmed that granite can accom. modate the thermal and mechanical loads imposed by a repository, exhibiting only small deformations that produce no apparent hazard to structural stability. In addition, we have found that existing thermal computer models adequately predict the response of the rock mass to the imposed loads; however, the mechanical and thermomechanical models are not adequate and must be improved.

\section{Recent ARAC Activities}

Since responding to the Three Mile Island accident in 1979, LLNL's At- mospheric Release Advisory Capability (ARAC) has provided its services in a number of other incidents, exercises, and alerts (Table 1). In 1980, two of these incidents occurred with no advance notice. On the morning of May 21, 1980, a cracked pipe in a storage tank at the Savannah River Plant released a smal] quantity of toxic hydrogen sulfide gas. Because the total amount of gas stored in the tank posed a potential hazard, local officials suspended highway, rail, and river traffic in the area while plant engineers sought to contain the danger. As an additional precautionary measure, ARAC support at the Savannah River Plant site was requested.

At the Plant, staff members prepared real-time calculations of likely plumetransport routes and diffusion rates in the event of an external release of the gas. Then, as the threat stabilized, they estimated probable drainage flow and associated plume-transport routes under nighttime meteorological conditions to anticipate the most likely zones of public risk; Fig. 5 shows a calculated isopleth pattern for the hydrogen sulfide gas. Fortunately, it proved possible to eliminate the hazard by means of an engineering 
Fig. 5

Inpinth pattern of the instantaneons atmenteric concentration of hydrogen swMre gas 2 in above ground level near the Savamah River Plant, calculated for 3 h after commencenent of a simulated continuous leak. The isopleths are in wits of ppm (parts of gas per million parts of air) ranglng from 1 to 1000 .

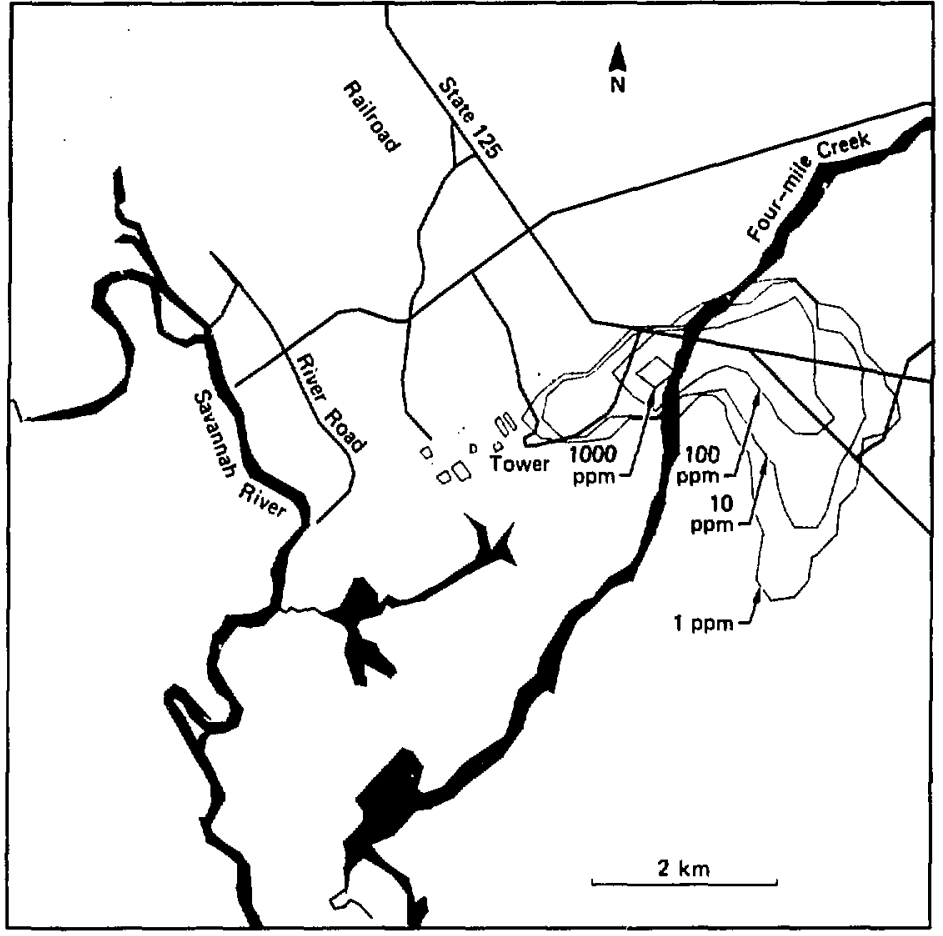

solution. The ARAC staff provided support throughout the eight-day duration of the incident.

ARAC's second response to an incident with no advance notice was on September 19, 1980, when a Titun II missile silo accident near Damascus, Arkansas, presented the possibility of a release of radioactive material. Our task in this case. using newly developed capabiiities, was to compile essential files on local

topography, meteorological stations, and geography. We also generated a series of alternutive scenarios to bracket the potential hazard.

A third incident, in which ARAC's participation was planned, was the purging of radioactive krypton-85 gas from the Unit 2 reactor-containment building at Three Mile Island. Our participation in this event was extensive. ARAC's primary role was to provide an indeperident assess- ment sy.tem to support the Environ. mental Protection Agency and the State of Pennsylyania during the planned releass. For (wo weeks preceding the purge, we conducted numerous tests and exercises: subsequently, (welve 24-h days were spent in supporting the calculation and ditti-collection efforts. Heliconters and mobile measurement systems were deployed to confirm our calculations.

As a result of ARAC's successful purticipation in the Three Mile Island operations and the two incidents for which there was no advance notice. plans are now being formulated to expand the scale of its activities. Round-the-clock emergency services will soon be available to agencies of Federal, state, and local government in accidents entailing the potential or actual release of radioactive materials to the atmosphere. 


\section{Nuclear Regulatory}

\section{Commission Projects}

As the number of nuclear power plants around the world has increased. there has been growing concern about the safety of reactors. In support of the Nuclear Regulatory Commission (NRC), scientists at LLNL are providing technical assistance in reactor safety by studying such diverse factors as earthquakes, engineering problems, and humiln behavior as they affect the operation of nuelear power plants, and by evaluating various provisions for safeguarding special nuclear milterial.

Recently, LLNL completed extensive tests and analyses to define the airtransient loading on parts of a boilingwater-reactor pressure containment system. These loads, which result irom fluid forces eaused by a pipe break (i.e., a loss-of-coolant accident), were studied using our one-fifth-scale MARK I Pressure Suppression Experiment. After this work was completed, the Nuclear Regulatory Commission decided to make use of information from foreign reactor-safety research programs, and LLNL was designated as the principal liaison to these programs.

Because earlier investigations have revealed that significant theoretical difficulties are encountered when reducedscale steam iest data are applied to fullscale plants, our liaison efforts are focused on the full-scale containment research programs at the GKSS Forschungszentrum Geestacht GmbH. West Germany (GKSS-PSS program), and at the Japan Atomic Energy Research Institute, TokajMura (JAERI-CRT program).

It soon became clear that we could not provide satisfactory information for the NRC by simply reviewing test data reports. We have, therefore, adopted an approach wherein we (LLNL) are a responsible part of the research staff for each of these foreign programs. By visiting and working on these projects, consulting on the measurement systems, revieving the raw data, and participating in the design of experiments, we are able not only to contribute to the research being done but also to improve the information flow to the NRC. This approach has been well received by the management

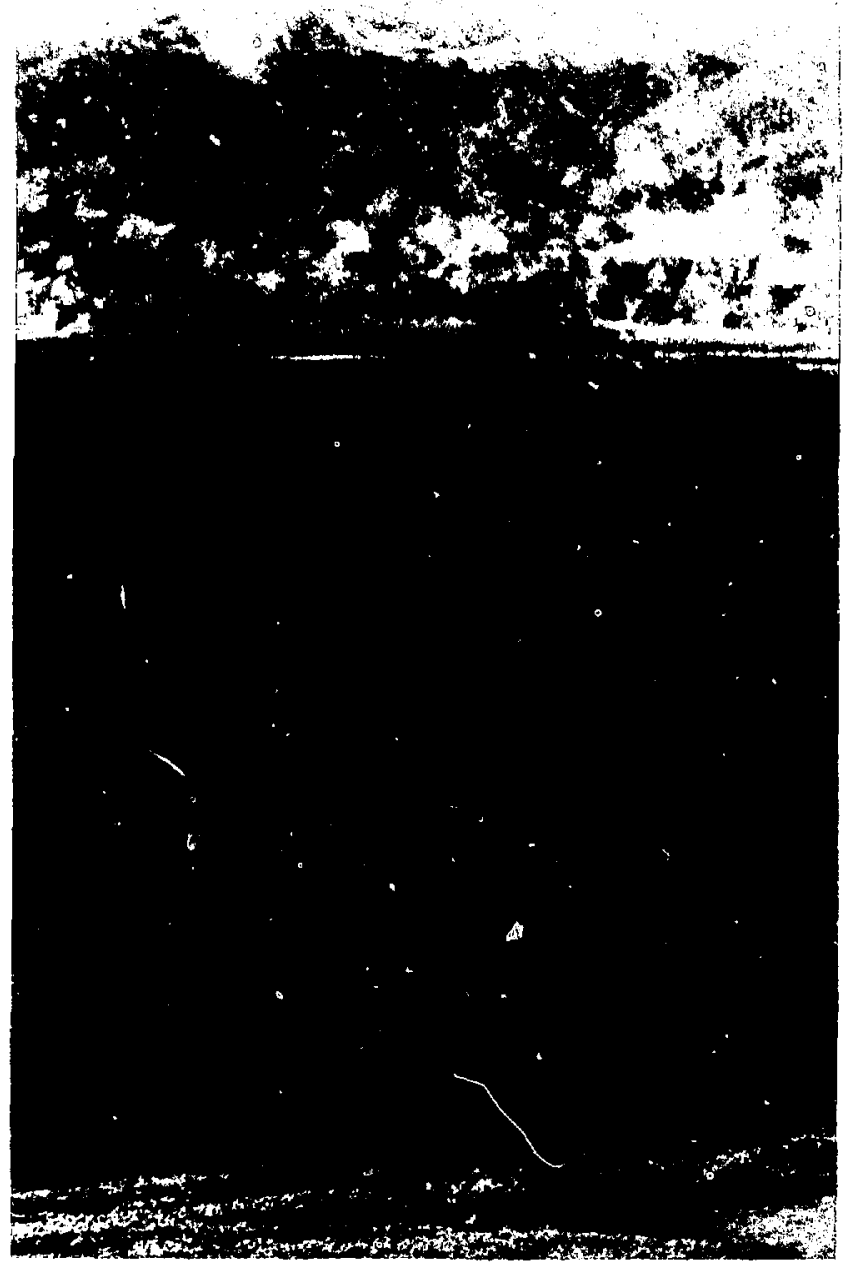


and staff of both programs so that we are in a very real sense engaged in two fullscale reactor-containment test programs, one in West Germany and one in Japan.

The primary purpose of our liaison with these two foreign programs is to develop an improved understanding of steam. condensation processes and to better define the associated load functions in the multivent pressure suppression system. To these ends, GKSS-PSS is providing us with subsets of their original data tapes. We have developed many computer programs, drawing on our earlier pressure suppression experiments, that enable us to exploit LLNL's advanced computing capabilities and perform extensive timeand frequency-domain inalyses of the data.

We are also assisting in the design of the measurement systems used in both foreign programs to ensure that the data obtained are as accurate and as complete as possible. Because the pressure measurements arc of particular importance, we at LLNL developed a technique for desensitizing pressure transducers to temperature transients (enabling them to be used in conditions with varying temperatures). This method has been extensively applied at the GKSS-PSS program and has yielded valuable data,

We have also assisted in the application of a rod lens (used in our earlier pressure suppression experiments) in the (iissSPSS facility that permits viewing of the steam-condensation processes during each experiment. With the aid of this device, we expect to obtain data that will increase our understanding of the source of the highly dynamic and oscillatory loads that develop during a loss-of-coolant accident.

In the near future, we will use techniques developed at LLNL to measure the natural frequencies and mode shapes both before and after the walls of the JAERICRT test facility are stiffened. These measurements will provide useful information applicable to the response of a full-scale reactor facility to loads applied by fluid forces that occur in a loss-ofcoolant accident.

\section{Summary}

LLNL's Tandem Mirror Experiment demonstrated a breakthrough in plasma confinement last year that has justified a complete revision of our magnetic fusion energy development timetable. The

MFTF-B machine, scheduled for operation in 1985, approaches the size and complexity of a fusion reactor and is expected to demonstrate break-even plasma conditions over relatively long periods of time (30s).

In the last year, our laser isotope separation program has brought the primary technology for this important new process to the stage where a major engineering effort can be directed to the development of equipment to provide a production cupubility for special nuclear material.

We have tested a full-size aluminum-air power cell, demonstrating that the electrochemistry of small test cells is amenable to scale-up. We have also successfully tested the operation of the cell stack and crystallizer together. An experimental battery based on these results has potential as a power source for electric vehicles with the range, acceleration, and rapid-refueling capabilities of conventional automobiles.

The major emphasis in our biomedical program has been on sludies of genetic injury and cancer-related biology in humans. A significant fraction of our environmental effort has been devoted to assessment of the impact of geothermal resource development.

In the first year of a five-year test, we have demonstrated that spent fuel from commercial reactors can be safely and reliably encapsulated, transported, placed into, and retrieved from deep geologic media using current technologies and have confirmed that granite rock can accommodate the thermal and mechanical loads imposed by a repository.

Since responding to the Three Mile Island accident in 1979, LLNL's Atmospheric Release Advisory Capability (ARAC) has provided its services in a number of o:her incidents, exercises, and alerts.

As part of our work for the Nuclear Regulatory Commission, we are monitor. ing reactor-safety experiments being conducted in Germany and Japan. 녕 
Key words: air polfution: aluminum: ARAC: Atmospheric Releuse Advisory Capability; boiling water reaclors; cells-analysis, effects of radiation: cytology-automation: electric batteries; electric vehicles: flow cytometry: geothermal development; instrumentation: land-use mojels: laser isotope separation; magnetic fusion e'lergy; MFE: MFTF-B: Nevada Test Sitc, nucleur safely: radioactivitymeasurements: reactor fuel: reactors-contuinment vessels. pressure suppression systems, safety: spent fuel: spent-ruel storage: toxic chemicuis-measurements: TMX.

\section{Notes and Referenecs}

1. "TMX Experimental Rcsults," Energ,y and Technology Review, UCRL-52000-81-6, June 1981. p. I.

2. "The Tundem Mirror Fusion Test Fucility." Energ! and Technology Review. UCRL-5200080-7. July 1980. p. 1.

3. "Mirror Fusion Reuctors," Energy' and Techmology Review, UCRL-52000-78-9, September 1978. p. 31.

4. "Diagnostics Instruments for Mirror-Confined Fusion Plasmis," Energl and Technology Review; UCRL-52000-79.8, August 1979, Р. 17.

5. "Computer Modeling of Magnetic Mirror Experimenis." Energy and Technologl Review, UCRL-52000-80-12. December 1980, p. 15.

6. Aluminum-air batteries are discussed in the November 1980 issue of the Energy and Tectholag! Review: UCRL-52000-80-1I, P. I, and in "The Aluminum-Air Battery for Aulomotive Propulsion," J. F. Cooper and E. Behrin, Lawrence Livermore National Laboratory, UCRL-85448 (presented at the Electric and Hybrid Vehicle Adyanced Tcchnology Seminar, Pasadenu, CA. Decem. ber 8.1980 ).

\section{Spent fuel from commercial reactors can be safely and reliably encapsulated, transported, placed into, and retrieved from deep geologic storage using current technologies.}



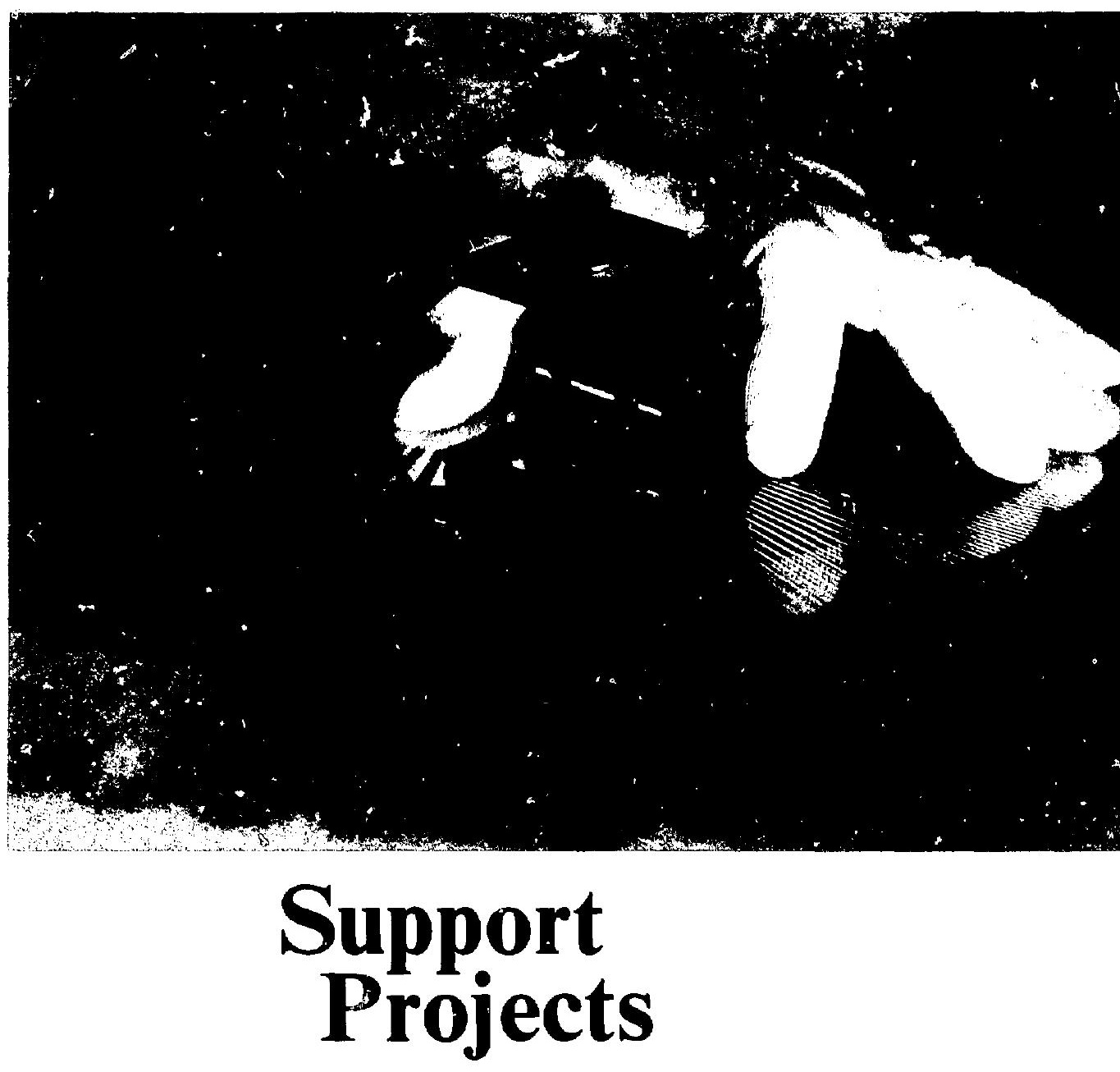

A sampling of recent achievements by LLNL support organizations indicates their diversity, their technical sophistication, and their importance.

The research programs at LLNL (weapons, magnetic fusion energy, laser fusion, biomedical and environmental, and energy and resource programs) call upon various support organizations for help in meeting their objectives. These support organizations, defined for the most part in terms of areas of technical specialization (such as chemistry, physics, engineering, and computation), are a 
valuable asset io the Laboratory because they keep pace with developments in the various disciplines and provide pools of well-trained professionals capable of lending their expertise to the new and constantly changing technizal problems faced in the ialajor reseurch programs.

The Laboratory's organizational structure can hest be described as a matrix, in which individual personnel function not only under the direct and immediate supervision of a particular progran but often under the general administrative umbrella of a support organizution. For example. a group of engineers assigned to focus on the problems of inertial confinement fusion would function under the immediate supervision of the progralm itself while retuining membership in the broader engineering departments, to which they would look for general professional guidance and support (and for al new assignment when the immediate programmatic tasks are coinpleted). Our matrix organization, one of the oldest in the country. was designed to allow the fullest and most effective use of employees' skills while affording great flexibility as programmatic needs change.

The Laboratory's support organizations carry on sophisticated theoretical and experimental projects, many of which have applications thet serve not only LLNL programs but also the inteiests of the broader technical community. Thus, investigations into the tensile strength of a polymer fiber conducted by a support group in connection with a particular Laboratory program may also be of help to industries seeking a light and durable packaging material. A new instrument developed to measure irregularities on a polished optical surface that will be used as a laser target may provide engineers outside the Laboratory with a tool for refining other optical devices.

The six projects described in this article provide a sampling of the diverse support activities performed by the chemist ry and materials science, computation, physics, and engineering departments at LLNL during the past year. They include work on the structure of Kevlar fibers, light propagation in optical fibers, mechanisms influencing gun-barrel erosion, structural models of the giant planets, optical surface profilometry, and a unique computational facility for the mugnetic fusion energy program.

\section{Determining the Structure of Kevlar Fibers}

Fiber/epoxy composites are being used to make strong, lightweight structural components that are expected to maintain their structural integrity for years. Graphite, glass, and boron fiters have been avialable for several decendes, and their structures and mechanical properties are well known. However, fibers of poly(p-phenylene terephthalamide), or PPTA, which is manufactured by duPont as Kevlar, have been available only in the last decade. Thus, the properties of this material, especially its durability, have not been completely defined. Accurate prediction of fiber durability requires a detailed understanding of the physical structure of the fiber, how the structure relates to the deformation and failure mechanisms ohserved. and how this relationship is modified by the service environment. The LLNL Chemistry and Materials Science Department is investigating the relation of Kevlar structure to fiber deformation and Pailure.!

The primary sponsors of this work have been the Nuclear Weapons Program. the Nonnuclear Ordnance Program, NASA, the European Space Agency, and the DOE Energy Conservation Division. The applications include Mexible armor. pressure vessels. satellites, motor cases, dircraft components, flywheels, tankage, and surface transportation components, among others.

Kevlar fibers are formed by spinning filaments of warm PPTA-sulfuric acid solution into a colś-water coagulation bath. During cooling, the interior of the cylindrical PPTA- $\mathrm{H}_{2} \mathrm{SO}_{4}$ dope crystallizes, whereas the rapid cooling of the exterior results in a noncrystalline skin. Subsequent treatment of the solidified dope involves $\mathrm{H}_{2} \mathrm{O}-\mathrm{H}_{2} \mathrm{SO}_{4}$ exchange in the water coagulation bath. sodium hydroxide neutralization of the $\mathrm{H}_{2} \mathrm{SO}_{4}$, washing of the resultant $\mathrm{H}_{2} \mathrm{SO}_{4}$ with water, and drying of the fibers at $65^{\circ} \mathrm{C}$. After drying, the fibers have a modulus of $65 \mathrm{GPa}$ and are referred to as 


\section{F.g. 1}

Scaning electron photomicrograph of the axially fractured surface of a Kevlar 49 rber, revealing the presence of periodically occurring, internal transverse planes (red). These planes, rormed when the PPTAsulfuric acid solution is splun into the coagulation bath and erystallized, constitute an inherent weakness in the Kevlar fibers. There are no such planes in the outer skin (blue) of the Tiber because Its constluent molecular chains end at randomiy distributed points.

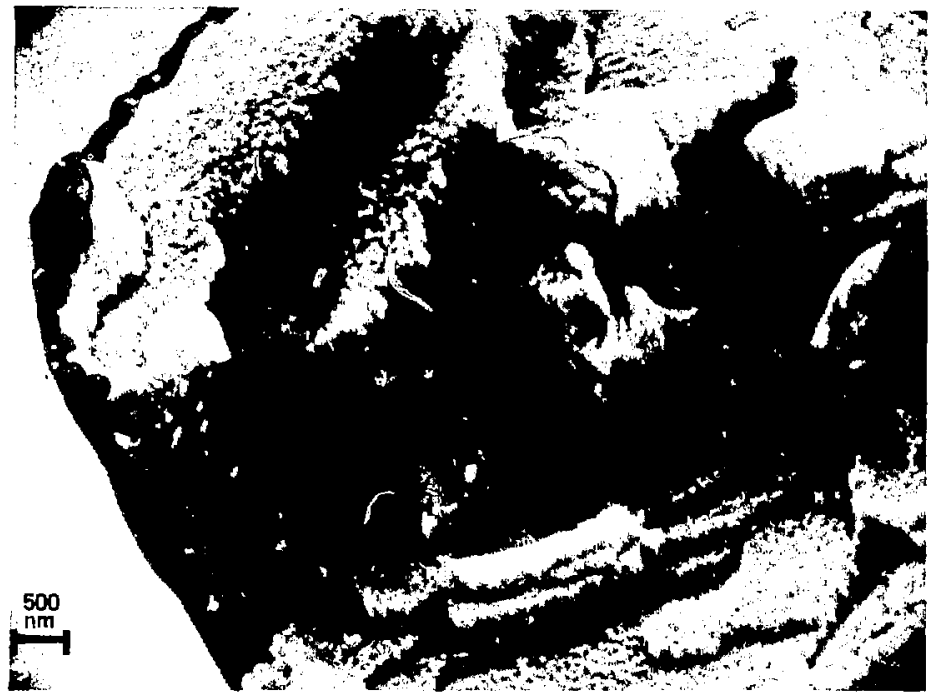

Kevlar 29 fibers (used in automobile lires). Further heat treatment at $550^{\circ} \mathrm{C}$ under stress aligns the PPTA molecules more nerfectly, doubling the fiber modulus to $125 \mathrm{GPa}$; this produces Kevlar 49 fibers.

Electron photomicrographs of Kevlar fibers reveal that the bulky, ionic end groups of the PPTA molecules cluster in planes upon crystallization (Fig. 1). These internal planes occur about every $200 \mathrm{~nm}$ (the average PPTA molecular length) along the fiber axis. Howevar, ' $n$ the noncrystalline skin, the bulky enc groups are nearly randomly distributed. Thus, in the longitudinal fiber direction, the skin has more continuous structural integrity than does the crystalline fiber core.

We have found that Kevlar fibers, in the form of unimpregnated yarns and epoxy composites, fail under tension by splitting longitudinally 200 to $700 \mu \mathrm{m}$ in the direction of the fiber length. After prolonged periods of stress, the fiber ages, and the fiber split length decreases as a result of macromolecular chain scission.

The fiber split length's are predominantly controlled by the noncrystalline skin with its nearly random chain-enc distribution. Therefore, any damage to this skin (e.g., during fabrication of the composite or during composite deformation) will degrade the fiber strength. Our studies have indicated that a strong bond between the epoxy matrix and the Kevlar fiber in the composite is undesirable because such a bond may damage the fiber skin.

Wo have used transmission optical microscopy of Kevlar 49 Sit irs to study transverse defect planes in the fiber core occurring periodically along the fiber axis. As expected, these planes become more pronounced under tensile stress. We have observed two distinct deformation processes when Keviar 49 fibers are stressed under tension. In the first, each internal defect plane deforms nearly equally, and the fiber skin deforms uniformly. In the second, certain defect planes deform considerably more than others, and a portion of the skin adjacent to one of these defect planes fractures and peels, away from the fiber core. We believe that these skin-core deformation processes, which are consistent with our fiber model, involve both slipping and breaking of the PPTA molecular chains.

Further studies are being conducted to correlate PPTA fiber structure with fiber 
strength. We are also monitoring the breakage of PPTA molecular chains under various service environments using electron spin resonance spectroscopy. These studies will enable us to describe the durability of the Kevlar fiber in terms of molecular structure and failure mechanisms.

\section{Light Propagation in Optical Fibers}

During the past decade there has been an explosive growth in the use of hair-thin glass fibers to carry information coded into pulses of light. ${ }^{2}$ This rapid growth has been spurred by the many technical advantages offered by uptical fibers. including their small size, low weight, immunity to electromagnetic interference. and high information-carrying capacity. Fiber-optics technology is being used in the telecommunications industry, in the planned MX missile complex, in the LLNL Shiva laser fusion experiment,and in nuclear experiments at the Nevada Test Site.

In support of Department of Energy (DOE) defense programs at LLNL (but with many different applications in mind), the LLNL Physies Department has developed over tle past feu years a very accurate and complete wave-optics description of light propagation in optical fibers. In any waveguide structure, the propugated light can be resolved into a number of normal modes (i.e., simple vibrations with an unchanging shape and rate that combine to form the total field, which is constantly changing). In the past, attempts have been made to calculate these individual modes directly. Our method, called the propagating beam method, differs from other upproaches in that it determines the total, multiple-mode field. The individual modes may be recovered a posteriori through Fourier analysis of the transmitted field. That is, a kind of numerical spectroscopy allows the calculated field to be decomposed into its constituent modes.

We have checked the propagating beam method extensively for accuracy by comparing it with analytic solutions where they exist. Individual mode shapes, propagation constants, and modal group velocities all show excellent agreement for those cases where comparisons could be nade. This increases out confidence in applying the method in other cuses. Our approach has been used to address a number of significant practical questions, including dispersion (the spreading of pulses over time. leading to a blurring of distinctions), signal altenuation, and the effect of splices.

The propagating beam method gives an accurate description of light propagation and dispersion in realistic optical fibers, it may be used to study other waveguide systems as well, as its recent application to optical resonators has shown. The method provides a powerful tool for understanding basic properties of waveguides and should lead to a variety of practical applications.

\section{Mechanisms Influencing Gun-Barrel Erosion}

Modern chemical propellants produce higher temperatures and pressures in the firing chamber of cannon than do conventional propellants. ${ }^{3}$ If the fit between the barrel and the projectile is correct, the higher pressure makes it possible to fire a projectile with increased momentum (1.e., vither greater mass or higher muzzle velocity), thus increasing range and penetrating power. At the same time. the combination of high temperature and pressure results in increased hetl transfer and stress, which may ciuse the gun barrels to wear out much faster than they do with the conventional propellants. The Physics Department hus undertaken for the Department of the Army a three-year program of fundamental erosioncorrosion research to determine the processes affecting the erosion of largecaliber cannon barrels.

Using a 14-MPa pressure chamber, we are testing the influence of various combinations of combustion-gas components on selected materials subjected to elevated pressures and laser-heated to high temperatures. We expose a variety of hightemperature-resistant metals to inert gases such as argon, chemically active gases such as nitrogen, oxygen, and hydrogen, and gas mixtures such as air, carbon monoxide, and carbon dioxide. By 


\section{We have undertaken a three-year program of fundamental erosion-corrosion research . . . to determine the processes affecting the erosion of iarge-caliber cannon barrels.}

we are currently examining the hypothesis that the nicktl layer damps the thernalstress-induced shock b! providing a gradualed shock-mpedance later, thus, in effect. spreading the pulsc energy absurption wer the longe-term heating and couling sele. We are conducting additional experiments lo reproduce and verify these anespected ferults in part of our contintultwg work on retrictors biltinges.

(iun-barret erosion cin also he conIrolled by allermg the thin gas boundar! liner adjictent to the metal surfile. Mons of the gals in the firing chamber is very hol and lurbulent, hut the gats in contace " ith the antually coul hatrel surlike is relativel! cool and almost stationaly. The ratte at wheh heill can be delivered lo the erosion mechantsums at the metal surliate depends (II) the temperatlure gradiem, which in turn depends on the thick ness of the zats bouidarsy latser. Therelore. lhickening the gis houndary layer should help to reduce crovion of the gutu harrel. We halce delermined, both experimentally and theoreticalls, that adding submicron-sided parlicles of talcs, silicit. or titanium dioside (1) the lurbulent combustion gas thickens the boundary layer, therehy reducing the cemperallure gradient and the correspronding heal trinsfier. We are able 11 atralys ahis lurbulent gas with the aid af Schlicren optics, adtanced lascre doppler anemometrs, and TRAVIS, a computationally dificisat turbulent-gasdynanics code that permits us lor the first lime lo melude the large number al variables necessitry to deseribe limedependent turhulent fou adequitely. renctions on the metals, "we should clues to the influence of both the erosive-corrosive aspects of the gass environment and the response and resistance of particular mitterials to the environments.

One way lo minimize geun-harrel erosion, or it least reduce it. is to matke the metal surface less reatetive. For this reatson, our experiments using steel that is coated with a refractory layer are very imporiant. We coated steel targets with a thin layer of nickel to increase adherence. Over this, we deposited a thick laver of refractory tungsten for heat resistance. We discovered that the thicker the nickel layer, the longer the tungsten layer lasted and the longer the steel was protected. Of the many possible reasons for this result.

\section{Shock-Wave Studies for Modeling the Giant Planets \\ I. NI. hals a long-standing restarch} program using shock-wate experiments and theory (o provide eyuation-olf-state datal for many elements and materiats wer a hroad range of pressures and lem. peralures. These methods. developed by the Physics Department for DOE defense programs. have proved useful also for medeling the giant planets.

The recent fights of Pioneer and Voyiger to Jupiter and Saturn, as well as the anticipated visits to Uranus and Neptunc, have stimulated interest in the strue- 
fure of these planets. They are known to differ markedly from the "isll-studied inner planets, and observattions of their aserage density, grasitational moments, and atianspherit composition have thabled researchers bo dran winc conclusions as lo their structure. Honcerer, these elforts are halmpered by the i.tch of alscurate datil on the chemeat. phosical, and thermendy namic properties of the constjtuent matcrials all the extromely hegh temperatures and pressures characteristic of the ptinetar? intoriors.

Ai the present time. the giant plitnets are thuught lo consist of three laysers: a top layer of molecular hrdrogen and helium: a middle liỵer of either metallic hodrogen and helium (for Jupiter and Siturn) ir ies Mater. methane. and ammoniat (for Uranus and $\left.N_{(}, u n e\right)$ and a rucks sore of iron, nick .., in s in, and mignesium oxides. To ireilte inituctural moulels that correctly a t the ohserved charalcteristics of these gatm planets, we must hats accurate equations of statc. phase diagrams, and electrical conduclisities for all these malerials over an extremely wide range of physical conditions. (An equation of state defines the relationsh,p of pressure. density. and temperatture for al given material.j

The water and methane environments of Uramus and Neptune resemble the ultimalte product of high-explosive detonation. and the abundiance of hydrogen and helium on the giam planets makes them interesting to restarchers working on fusion devices. Recently conducted shock"ave experiments have enabled us to develop more accurate equations of stitle for many of the giant-pianet mitterials. and these equations of state hate, in turn, made models of the giant planets more ilccurate."

Most of the shock-wave dala used to model the giant planets were obtained with the LLNL two-stage gas gun. This device can accelerate a 20 - $\mathrm{g}$ metal projectile against a iatget al velocities up to $8 \mathrm{~km} / \mathrm{s}$. To achieve conditions comparable to those in the planetary interiors. hydrogen. methane, ammonia, and water must be shocked from their liquid phase. The first three materials have boiling points below room temperature, and thus these targets are actually small cryostats.
When the projectile hits the larget, it generates a ingh-pressure shock " ilve thall momentarily compresses and heats the target material (i.e., Huganiot compression) into the pressure-tenuperature regiun of interest. The properties of the material afs meinitiod diring the brite instant. To (w):ain even higher pressures. we use a reflected-shock technigue in which the primasy showek is pissicd through this tareget malcerial and llien rellected off an anvil (c.g., a brass platte). As the relleeted shoch salle piasses back throught the targel, It further compresses the larges material. B? tarrying unt a series of reflected-slieck experintents, it is possible (1) " iden the range of our experimental datti, and make subseyuent theoretical exlensions of the curves norte alcurate

Usinge experimental and theoretisal tecturiques. we hatse esplored the therntodyatmic propes ', of the basic constittent materials of the giant planets. thas making as:ulable the dala for more alccurate models of plathetary srecture. We recently eonducied single-shos'k esperr. ments on deuterium that abtinged previsures up le 20 GPa (I). 2 Mhars and rellected-shich experments that reached 
Fig. 2

The Meterndyes swface proftometer ne hate recently deneloped use a split laver man to menwe wefuct irregulatitios on winly polished optical wrfaces. Surface variations of as little an $\mathbf{l . I}$ na can be defected from the wift in phawe hefweet the ino halves of the beam when twe half of the heam in focused an o fined refetence point i I on the optical wrface in Ar mencured. und the other half : H) desrrities a circular puth on the surface as the vample rntales.

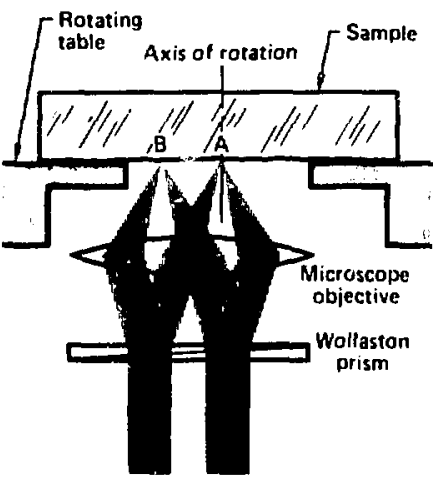

\section{We set out to develop a noncontacting, non- destructive instrument that would measure the roughness of an optical surface to an ultimate sensitivity of $0.1 \mathrm{~nm}$.}

k1) GPa (1). Mharl and 7(KM) K. We have also pianned two more reflected-shock experiments on denterium that will reach presuren between 20 and so GPa.

Mare alcerate madels of the giant planes atwai further theorecteal rescarch an the metallic phase tramsition and ther. mody natmose of dellse hydrogen and

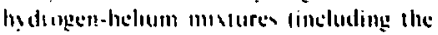
whobilits af helium in indrogens, the opicily of dense hy diropen. ant the shemsiry of ace and rocks - sors componelles ill hygh presellew almel lemperallures.

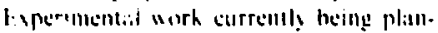

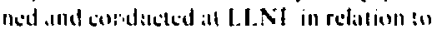

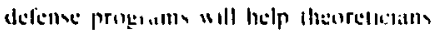

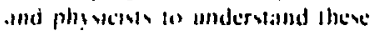

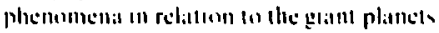

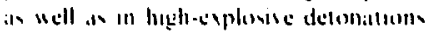
ind nucleat fusion in gentrial.

\section{Optical Surface Profisometry}

In the manuficture of precision optical proms, lenses, alsd murrors. (and leaturse of the uplicil surfitic-its shape and its rinsh-must he ciarcfull! tomstrulled. The gronding and pols hing processes normally uned la create these varfaces canment he predetermuned yuantitalis ely by a numerical model ar Iethnigice so uptics must he repeatledly polshed and tested until the devired varfice is obrained. We cill meisure the valpe of the surface vatisfictoril! with evisting methanical vylus instruments os by meadns of optical enterferometry, hut metsuring its finish is niste proflemitic. Tecleniques currently used are olien cumbersome. slow, allad inufficiently xemvitive. Thes rels on statistical meisurement of the surface (scatterometry). or they require that the virlice he cllalled, contacted. or compared to a reference whose properties are similar and also unk nown.

Opticial surface finish. or roughness. and the ahility to measure it preciscl! atre importint when the optic is required to have a low stray light level and to resist damige from laser radiation. These $r e-$ quirentents apply. for instinct. to components for inertial confinement fusion laser sources, astronomical systems, highquality imaging and surveillance systems, and other high-precision applications.

The LLNL Malerials Fabrication Division optics group under the auspices of 
(a)

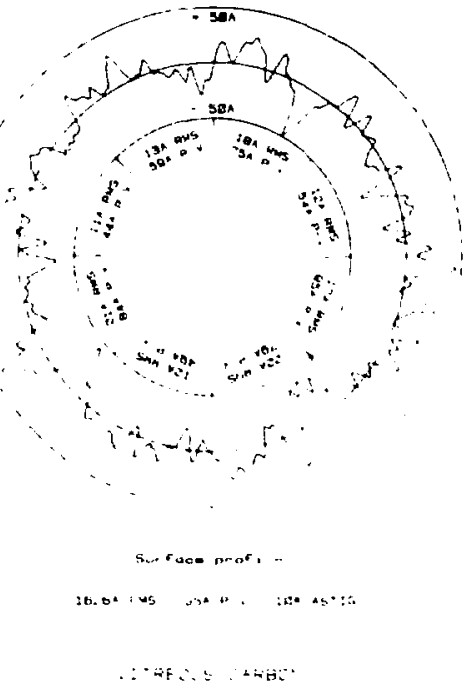

(b)

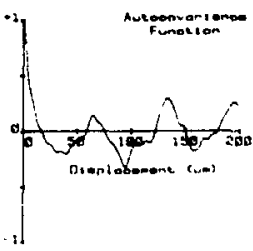

(d)

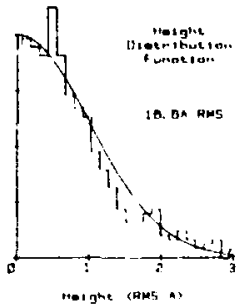

(c)

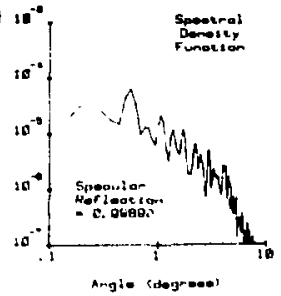

(a)

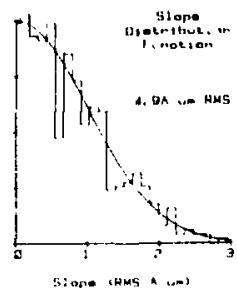

the Mechanical Enginecring Department set out to develop an instrument that would quantify the roughness of an oplical surfatet to an ultimale sensitivity of $0.1 \mathrm{~nm}$, he noncontacting and otherwise nondestructive, require no referente surfastz, and be moderalds toleranl of environmentat influences commonly found in an optical laboratory. Our concept is based on principles of heterodyne interferometry. ' An axial magnetic ficld. applied to the plasima tuhe of a heliumneon laser. splits the be:tm into two orthogonally polarired beatms of slig̨htly different frequency. stabilized to al erı stal reference. These beams are then focused at two poiris on the surface to be meisured. and the surfatce is rotated on an air bearing table. One of the points. focused at the center of the rotilting specinien (see Fig. 2). is used as al reference, and the other is made 10 scin a sinall (about $200 \mu \mathrm{m}$ diam), circular path around $x$ (in about 30 s) as the sample is rotaled. Variations in the sample surface height. averaged over the focal spot (about $2 \mu \mathrm{m}$ diam). change the point from which the scanned spot is reflected.

Thus, the optical path between the two beams changes as they pass through an in- lerferometer. This palth-length change will caluse a phase shift in the beat frequency seen by the test detector with respect to the reference detector. This phase shift can be related to a difference in the phisical height of the two spots. As the stanned spot is moved about the reference, the measured height differences form a circular profile of the surface being texled. The data thus obtained are plotted b) a compuler in the form shown in 1.ig. ?.

In addition to the basic circular path profile of a flat surface, this instrument cin generate statistical data about the surfice, e.p. the root mean square surface roughness, the peik-to-valley spin of the surfalce irregularities, the autocovariance function (a measure of the similarity of points on the surface as a function of the distance between them), the speetral density function (a measure of the relative amount of light that will be seattered from the test surface as a function of angle). and the height and slope distributions.

This instrument met or exceeded all our original design goals, and Industrial Research/Development magazine has recognized it as one of the .00 most significant technical products of the year."

\section{Fig. 3}

Typical computer-Rcnerated representation (a) of the irregula rities in an optical surface as they are sensed during one elrcular scan by the heterodyne surface profilometer. Dats gathered by the profilometer can also be uned to determine, among other things, (b) the aulocovariance, (c) the spectral density function, (d) height distribution. and (t) slope distribution of surface irregularities. 


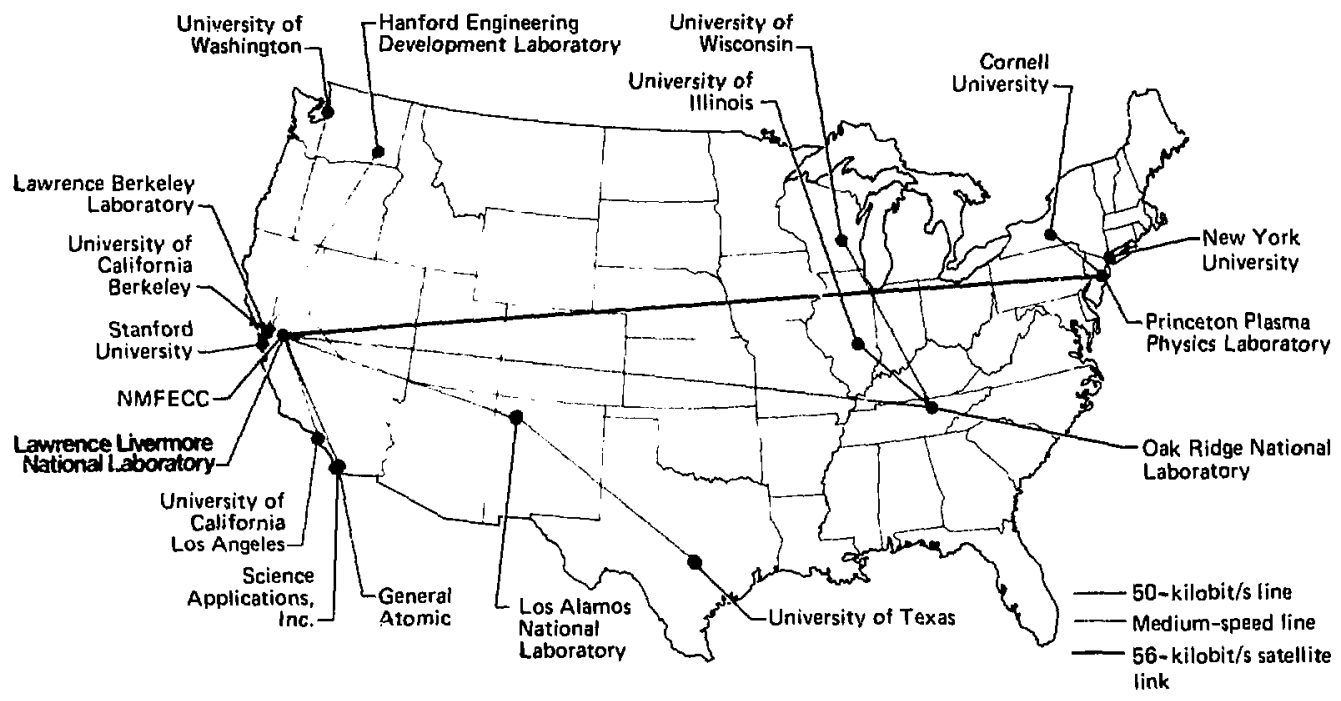

\section{Fig. 4}

Institutions engaged in respurch on magnetic fusion energy throughout the country are connected by a computer network headyuartered in the Yational Vagnetic Fusion Finergy Computer Center at I.I. VI.. The network makes the powerful Cray-l and CDC 76ay) computers at the Conter arailable to network members. It also pools and standardizes computer modeling codes developed througheus the nutional fusion community and makes them casily available to participating institutions.
We are currently working to adapt it for use on curved surfaces. in the expectation that eventually it may be applied to spherical or aspherical lens geometries or even to surfaces other than optical ones.

\section{The National MFE \\ Computer Center}

The National Magnetic Fusion Energy Computer Center (MFECC), with headquarters at LLNL. was established in 1974 by the Atomic Energy Commission and is now sponsured by the DOE Office of Magnetic Fusion Energy to make state-ofthe-art computational hardware and techniques available to reseurchers attempting to harness thermonuclear fusion. Access to this national computer network (represented in Fig. 4) enables participating institutions to exchange and standardize computer codes they have developed to model various fusion plasma phenomena. The network allows codes developed at one member laboratory to be applied to experiments under way at another and gives participants access to the Center's high-speed Cray-l and CDC 7600 computers. Its efficiency in calculating and dispersing results within the national fusion community has made it crucial to the continuing refinement of fusion theory and the growing ability to predict fusion experiments.

Users can access the large computers in several different ways. Service centers at Princeton University, Oak Ridge and Los Alamos, National Laboratories, General Atomic: Company, and LLNL are equip. ped with DEC-10 computer systems that provide direct, high-speed access to the Nittional Center through dedicated wideband data communications links. A dialup capability is provided at approximately 30 selected universities and laboratories engiged in magnetic fusion energy research. In addition, 15 remole job-entry stutions are in operation at sites designated by the DOE.

The National MFECC has elose ties with the Los Alamos and LLNL computer centers, and these ties have been strengthened this year. Cray timesharing systems at the three faciiities have been standardized, and common utility routines have been adjusted to make them more portable. The MFECC on-line documentation system is being reviewed at Los Alamos, and the formatting and content of many LLNL Computer Center documents have been adjusted to make them compatible with the MFECC 
documentation system. MFECC and LLNL compiler experts are working this year to extend FORTRAN syntax to array processing. Their report ${ }^{7}$ has been reviewed and approved by Los Alamos, LLNL, and the MFECC.

A 56-kilobit/s satellite link between the MFECC and the Princeton Plasma Physics Laboratory was established in April 1981. The performance specified for this system pernitted an error rate of 1 bit in $10^{9}$ bits over a 24 -hour period and availability of $99.8 \%$ over a one-year period. Early experience with the link suggests performance well within these limits. The sutellite service replaces a 50-kilobit/s dedicated Bell System line which had been in use since 1976 . The 50-kilobit/s Bell System lines to Oak Ridge National Laboratory, Los Alamos National Laboratory, and General Atomic Company continue to operate, but they, too, will be replaced with satellite service by November 1981 .

\section{Summary}

A sampling of recent achievements by LLNL support organizations indicates their diversity, their technical sophistication, and their imporlance. Studies of Kevlar fibers shoulj extend the usefulness of Kevlar/epoxy fiber composites in many applications where lightweight, highstrength materials are needed. Our mathematical description of light propagation in optical libers provides a powerful tool for understanding the basic properties of waveguides and should lead to a variety of practical applications. Studies of mechanisms influencing gunbarrel erosion have revealed a number of ways of controlling this destructive phenomenon. LLNL shock-wave research is deepening our understanding of the processes of fusion and high-explosive detonation and of the structure of the giant planets. Industrial Research! Development magazine has recognized our optical surface profilometer as one of the 100 most significant technical products of the year. Our National Magnetic Fusion Energy Computer Center is crucial to the continuing refinement of fusion theory and the growing ability to predict the behavior of confined plasmas. 4
Key Words; computer; fiber oplics; piant planets: gun-barrel erosion: Keviar fibers: Kevlar epoxy composiles: light propagation: magnetic lusion energy: matrix organization; modeling: National Magnetic Fusion Energy Computer Center: optical fibers; opticill virface profilomelry: shock-salve sludies: TRAVIS

\section{Vules and Koferences}

1. See, for example: R. 1. Morgan et al., *rhe Structure and Property Relationships of Polyg-

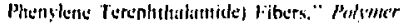
Proprims. American C'lemimial Suciels 21121. 2(14

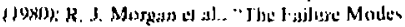
and Dutability of Kenlar-l pou Compunile"

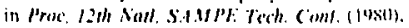
p. 3n'. and (c. 0. Prunedal et al. "Structure

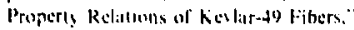
American Chemical Sociels Polvoner Preprems 22(2), In press.

2. "1.ight Propatgition in Oplical lïhers." Energr

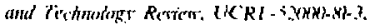
March 1981. p. 1.

3. "Restilrch on Gun-Barrel Iromon Mechanisms." Energy and Tethundege Reten. IICRI.-52(x)(1)-79-1, Jinuary 1979. 7.9 and "Mechanisms In nuencing Ciun-Birrel l rasion."

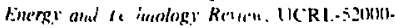
kI-3. March |9k|, p. 11 .

4. "Shock-Wave Studies: Modeting the a... nt Plinets," Energl and Techmology Rew'w. UCRL-52(Ko0-81-4. April 1900, p. I

5. Ci. H. Sommargren. "Oplical Helersdyne Profilometr." tppl. Opr. 20. $610119 \times 11$.

6. See atuard annorumement in heduscrial Revearih/levelopment 22. I 2 (1980).

7. C. Witherell. Arral Processigng for fORTRAt l.aurenet I.ivermore National I aburalory. (1) ID.30175 Res. I (1981). 
Listed below are articles published in recent issues of the Energy and Techology Review. They are grouped in terms of their relevance to the areas of responsibility of Assistant Secreturies of the U.S. Depurtment of Energy. with a few additional cattgories created for research funded by other agencies.

\section{DFFENSF. PROGRAMS}

\section{Inertial Fusion}

The Nowal Plasmbi Shulted (May lydu)

International Security Affairs

berifying the Test-Hist Treaties (Jume 19x/1

\section{Ntilitury Application}

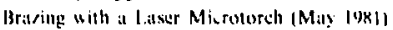

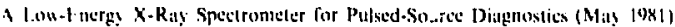

Micromachining (Mis) 1981)

Validation of the Pulsed-P'ower Design fin FXk (Ma! 19k1)

Shock- Wave Studies: Modeling the Giant Plancls (April lokJ)

t.ight Propigation in Optical Pihers (March 14\%l)

Flectrical Aspects of Raimoul (January 1981)

\section{FNERGY RESEARCH}

Tandem-Mirror Jind Plugs for Future Fusion Retators (Junc 1981) TMX I-xperimental Results (June 1981)

Thermat (antrol of the MFTF Supersond ueting Magnel (May 198I)

Flanc-Quenching in Internal Combustion tenpines (April IY8I)

Moudeling of Solid-State Materials for Solar Culls (April 14ㅈ)

Computer Simulations of Ion-Surface Interactions (Febsuary 1981)

Improving the Performance of High-Speed Compuler Networks (Fehruary 1981)

Making Beller Scientific use of Drill Holte (Fobruars 1981)

Microe:irthquakes in the Livernote Valley (February 19RI)

Physitutly Retasinabla Interpolation Melhods (February 198I)

Uncerground Imaging: Pietures of the World Below (Pehruary 1981)

Channeling Radiation (Janualry 1981)

\section{LABORATORY REVIFWS}

The lilectronses Enginer's Design Station (May jugl)

A Trihute to Nitholas (hristofilos (January 198I)

Using New Technolog! w Incrasse Fngineering Productivily (January 1981)

\section{NICI.EAR ENERGY}

The Chemistrs of (lranium Vapor (March 198I)

\section{WORK FOR OTHERS}

Defense Advanced Research Projects Agency

Advanced Test Accelerator Dedicated (Brief, January 1981)

\section{U.S. Army Research Ofice}

Mechanisms Influencing Gun-Barrel Erosion (March 1981) 